By

MARIA IVETTE CARBONI MALUCELLI

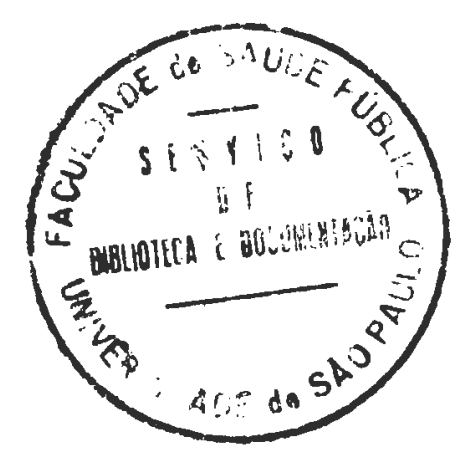

\title{
O MÉTODO POLAROGRÁFICO NA
}

\section{DETERMINAÇÃO DA VIABILIDADE DA VACINA BCG}

LIOFILIZADA




"Uma nova descoberta

é como uma criança:

\section{UMA PROMESSA"}

Louis Pasteur 


\section{Aos meus pais, \\ Ignácio Antônio e Angelina, por todo carinho, amor e orientaçāo desta vida.}

"O conhecimento científico pode ajudar a sustentar a vida, mas a vida é paixão, beleza e poesia." 
Aos meus filhos, Frederico Alexandre e Ricardo Juliano, por todo apoio, compreensāo, carinho, amizade, incentivo e muito amor.

Ao Prof. Dr. Benjamin Eurico Malucelli pela colaboração, dedicação, constante incentivo e amizade irrestrita.

A Isabelle e Fabiana Carboni de Freitas, minhas sobrinhas, assim como a seus pais Antônio Luiz e Claudete, por todo carinho, estímulo e apoio recebidos. 
Ao meu orientador

Prof. Dr. Rinaldo Niero

MINHA GRATIDÃO PELO ESTIMULO AMIGO, ORIENTAÇÄO, DEDICAÇÄO E CONFLANÇAA. 


\section{AGRADECIMENTOS:}

Ao Prof. Dr. Metry Bacila, coordenador do Curso de Pós-Graduação em Ciências Veterinárias da Universidade Federal do Paraná, pelo apoio, direcionamento no estudo da respiração bacteriana, estímulo e atenção dispensada, desde o início até a conclusāo deste trabalho.

Ao Prof. Dr. Pedro Hélio Lucchiari, do Departamento de Biofísica do Instituto de Biociências da UNESP, Botucatu, São Paulo, por todo apoio técnico na construção do polarógrafo, valiosas sugestões, disposição e incentivos decisivos.

A Degussa S.A. pela valiosa doação do fio de prata para a construção do eletrodo.

Aos Profs. Drs. Rubens Rosa do Instituto de Química, Mateus Sugizaki e Maria de Fátima Sugizaki da UNESP, pelas valiosas sugestões.

A Dra. Martha Maria Mutti Pereira, Diretora do Serviço de Bacteriologia do Instituto Butantan, pela amizade, empenho e atenção durante a realização deste trabalho.

A Magda Dezsa Cavalcanti Souza, Dulcinéia Bruzzo, Rosely Cabetti B. Alves, Wania A. Gusmão, Isabel C. Feijó, Silvia Z. Fauze Carlos e demais funcionários do Laboratório de Vacina BCG Intradérmica do Instituto Butantan, pela constante colaboração nos detalhes técnicos da produçāo e controle de qualidade da vacina BCG liofilizada.

Ao Prof. Dr. Omar Miguel e Prof. Dr. Jair Lício F. Santos, da Faculdade de Saúde Pública, pelas valiosas sugestões e atenção dispensadas na análise estatística deste trabalho.

A Denise Maria Mariotti pela revisāo das referências bibliográficas e funcionárias da Biblioteca e Setor de Xerox do Instituto Butantan, pela atenção que sempre me dispensaram. 
A Maria Aparecida de Paula e Antônio Martins pelo auxilio na confecção das figuras.

A amiga Eide Mariana Murta Carvalho pelo carinho, atenção e colaboração na revisāo do texto.

Aos amigos da Seção de Vacinas Bacterianas e particularmente a Valter Pezzine, pela estimulante amizade e espírito de colaboração durante este período.

Aos Profs. Péricles, Marilia, Gilberto e funcionárias Maria José, Lúcia, Elisa, Beth e Denise do Departamento de Epidemiologia da Faculdade de Saúde Pública, pela agradável convivência.

Aos amigos Dr. Medina, Marvina, Lotte, Tânia, Thalma e Ana do Laboratório de Piscicultura da Faculdade de Ciências Agrárias da Universidade Federal do Paraná, pela constante amizade e colaboração.

Ao Eduardo de Castro Bello pelo empenho e esmero na digitação do texto em computador.

Ao Leonardo van Halsema pela composição, diagramação e o "scanning" das ilustraçōes.

A todos que direta ou indiretamente me ajudaram.

MUITO OBRIGADA. 


\section{RESUMO}

Tendo em vista os vários problemas envolvendo a metodologia correntemente utilizada para a determinação da viabilidade no controle de qualidade da vacina BCG liofilizada, foi levado a efeito um estudo a respeito do assunto. Foi procedido um estudo de métodos alternativos a serem empregados em procedimentos de controle de qualidade da vacina BCG liofilizada. Com esse objetivo foi desenhado e construf́do um polarógrafo de eletrodo de oxigênio constituído de eletrodo de platina e o de referência de $\mathrm{Ag}-\mathrm{AgCl}$ embutido em peça única e ainda dotado de sensor de temperatura, com circuito eletrônico permitindo a medida de consumo de oxigênio. Levouse a efeito, então, estudo comparativo de viabilidade de vacina BCG liofilizada pela medida polarográfica de consumo de oxigênio em comparação à manométrica pelo clássico método de Warburg e o método de contagem de colônias (UFC). A análise de 66 diferentes lotes de vacina BCG liofilizada produzidas pelo Instituto Butantan, São Paulo, e pela Fundação Ataulpho de Paiva, Rio de Janeiro, demonstrou que a técnica polarográfica revelou ser altamente reprodutível e muito mais conveniente que os métodos manométrico e de contagem de colônias. Verificou-se que entre o método polarográfico e o manométrico e UFC os resultados da regressão linear mostraram correlação positiva de alta intensidade e significante ao nível de $\alpha=0,05$, permitindo indicar o método polarográfico descrito, como procedimento de escolha para operações de controle de qualidade em laboratórios de produção de vacina BCG bem como em Unidades de Saúde, para determinaçōes adequadas de viabilidade de lotes de vacinas, a serem utilizadas para fins de imunizaçāo. 


\section{SUMMARY}

Considering the several problems regarding the procedures currently employed in the assays of the control of quality and the viability of the freeze - dried BCG vaccines, a study on various methods used for this purpose was carried out. Aiming to introduce a much more suitable, sensitive and less time consuming method than the classic Warburg technique and the colony count test (CFU) bacteriological procedure, currently used, a new oxygen electrode polarograph was designed with the aim of employing it for the study of the viability of the freeze - dried BCG vaccine. This polarograph electrode was built in a single piece containing the platinun and the $\mathrm{Ag}$ $\mathrm{AgCl}$ reference electrode besides a temperature sensor. By using this assembly a comparative study was carried on the viability of the freeze - dried BCG vaccine assayed by the polarographic method in comparison with the manometric and the CFU methods. The analysis of the viability of 66 different batches of freeze - dried BCG vaccines produced at the Butantan Institute, São Paulo, and at the Ataulpho de Paiva Foundation, Rio de Janeiro, demonstrated that the polarographic technique revealed to be highly reliable and much more convenient than both the manometric and the CFU methods: it has been found out that between the polarographic and the manometric and the CFU, the linear regression showed a high intensity positive correlation and significant at the level of $\alpha=0,05$. In this way, the polarographic method could be considered as a choice method for the control of quality procedure as well as for the establishment of the viability of the batches of vaccines to be used for human immunization in Units of the Health Department. 


\section{CONTEÚDO}

1 - INTRODUÇĀO........................................................................................................ 01

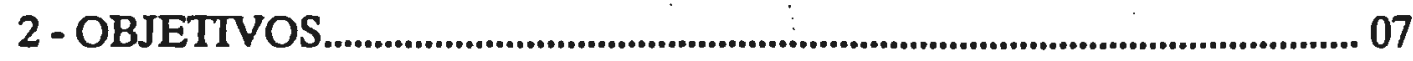

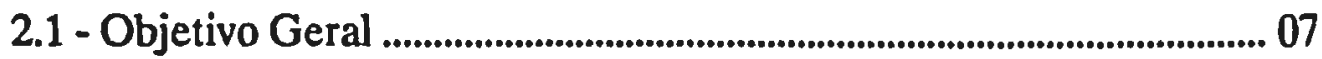

2.2 - Objetivos Especificos ................................................................................. 07

3 - MATERIAL E METODOS.................................................................... 08

3.1 - Amostras de vacina BCG liofilizada para a determinação da viabilidade................................................................................................. 08

3.2 - Técnicas empregadas para a determinaçâo da viabilidade da vacina $B C G$ liofilizada ................................................................................ 08

3.2.1 - Determinação do Número de Unidades Formadoras de Colônias (UFC), pelo método de contagem de colônias....... 08

3.2.2 - Determinação do consumo de oxigênio pelo método respirométrico de Warburg.................................................................. 09

3.2.3 - Determinação do consumo de oxigênio pelo método polarografico........................................................................................ 10

3.2.3.1 - Princípio do método ........................................................... 10

3.2.3.2 - Circuito polarográfico ....................................................... 13

3.2.3.3 - Termômetro digital.............................................................. 13

3.2.3.4- Agitađor magnético .............................................................. 13

3.2.3.5 - Polarógrafo ......................................................................... 13

3.2.3.6 - Sensor - Eletrodo combinado para oxigênio e temperatura.................................................................................. 14

3.2.3.7 - Câmara de reação ................................................................... 15

3.2.3.8 - Arranjo experimental ........................................................ 16

3.2.3.9 - Procedimento na determinação do consumo de oxigênio da vacina BCG liofilizada .................................. 17

3.2.3.9.1 - Limpeza e desinfecçăo da câmara........................ 17

3.2.3.9.2 - Estabilizaçāo do sistema.......................................... 18

3.2.3.9.3 - Reconstituição das vacinas e adição da amostra ......................................................................... 18

3.2.3.9.4 - Registro e quantificação....................................... 19

3.3 - Delineamento experimental ...................................................................... 21 
3.3.1 - Determinação do consumo de oxigênio pelo método polarográfico,em diferentes concentraçōes de vacina BCG liofilizada

3.3.2 - Determinaçāo do consumo de oxigênio pelo método polarográfico, de três lotes da vacina BCG liofilizada, submetida a diferentes temperaturas.

3.3.3 - Teste de diferentes diluentes para a reconstituiçāo da vacina BCG liofilizada.

3.3.4 - Estudo comparativo da viabilidade da vacina BCG liofilizada pelo método polarográfico, pela técnica respirométrica de Warburg e pela determinação do número de unidades formadoras de colônias (contagem de colônias)

3.3.5 - Avaliação da reprodutibilidade do método polarográfico em diferentes lotes de vacina BCG liofilizada.

3.4 - Análise estatística 22

4 - RESULTADOS

4.1 - Determinação do consumo de oxigênio pelo método polarográfico em diferentes concentraçōes de vacina BCG liofilizada....... 23

4.2 - Determinação do consumo de oxigênio, pelo método polarográfico, de três lotes da vacina BCG liofilizada, submetida a diferentes temperaturas

4.3 - Teste de diferentes diluentes para a reconstituição da vacina BCG liofilizada.

4.4 - Estudo comparativo da viabilidade da vacina BCG liofilizada pelo método polarográfico, pela técnica respirométrica de Warburg e pela determinação do número de unidades formadoras de colônias (contagem de colônias)

4.5 - Avaliação da reprodutibilidade do método polarográfico em diferentes lotes de vacina BCG liofilizada.

5 - DISCUSSĀO 36

6 - CONCLUSÕES 


\section{FIGURAS E TABELAS}

FIGURA 1 - Representação esquemática do circuito para medida polarográfica da concentração de oxigênio.

FIGURA 2 - Representação do eletrodo combinado para oxigênio e temperatura.

FIGURA 3 - Representação esquemática da cuba de reação utilizada na determinação do consumo de oxigênio da vacina BCG liofilizada...... 24

FIGURA 4 - Representação esquemática do arranjo geral experimental para determinação do consumo de oxigênio da vacina BCG liofilizada

FIGURA 5 - Traçado experimental em registrador (ECB- RB 202) utilizando o método polaragráfico.

FIGURA 6 - Representação gráfica do consumo de oxigênio da vacina BCG liofilizada, em função da sua concentração.

TABELA 1 - Valores do consumo de oxigênio, determinado pelo método polarográfico em diferentes concentrações de vacina BCG liofilizada e respectivas dosagens de proteína.

TABELA 2 - Determinaçāo do consumo de oxigênio pelo método polarográfico de 3 lotes de vacina BCG liofilizada, submetidos a diferentes temperaturas e tempos, assim como sua sobrevida

TABELA 3 - Estudo comparativo da viabilidade de "pool" de amostras de vacina $B C G$ liofilizada, segundo os métodos utilizados.

TABELA 4 - Avaliação da determinação do consumo de oxigênio da vacina BCG liofilizada ("pool"), segundo os métodos, parâmetros e aplicação de "t" pareado

TABELA 5 - Resultados da regressão linear da determinação do consumo de oxigênio e número de UFC da vacina BCG liofilizada ("pool"), segundo os métodos polarográfico c contagem de colonias.

TABELA 6 - Resultados da regressāo linear da determinação do consumo de oxigênio e número de UFC da vacina BCG liofilizada ("pool"), segundo os métodos Warburg e contagem de colônias

TABELA 7 - Resultados da regressāo linear da determinaçāo do consumo de oxigênio da vacina BCG liofilizada ("pool"), segundo os métodos polarográfico e Warburg

TABELA 8 - Estudo comparativo da viabilidade da vacina BCG liofilizada em diferentes lotes, segundo os métodos utilizados. 
TABELA 9 - Avaliação da determinação do consumo de oxigênio dos 34 lotes de vacina BCG liofilizada segundo os métodos utilizados $e$ aplicação de " $t$ " para médias independentes

TABELA 10 - Resultados da regressão linear da determinação do consumo de oxigênio e número de UFC dos 34 lotes de vacina BCG liofilizada, segundo os métodos polarográfico e contagem de colónias

TABELA 11 - Resultados da regressão linear da determinação do consumo de oxigênio e número de UFC dos 34 lotes de vacina $\mathrm{BCG}$ liofilizada, segundo os métodos Warburg e contagem de colônias...... 53

TABELA 12 - Resultados da regressão linear da determinaçāo do consumo de oxigênio dos 34 lotes de vacina BCG liofilizada, segundo os métodos polarográfico e Warburg............................................................. 54

TABELA 13 - Avaliaçăo do consumo de oxigênio em polarógrafo, utilizando solução fisiológica tamponada adicionada de $0,3 \%$ de Tween 80 , na reconstituição do pó vacinal, em 12 lotes da vacina BCG liofilizada em 98 testes realizados 


\section{1 - INTRODUÇĀO}

A tuberculose manifestada por lesōes ósseas na coluna vertebral foi constatada em restos humanos do perfodo neolítico, na Europa, na Ásia Central e no Norte da Rússia (PACHECO \& MAGAÑA, 1982) e continua, até hoje, como uma das principais doenças que aflige a humanidade (MURRAY et alii, 1990).

O agente etiológico da tuberculose, o Mycobacterium tuberculosis, foi descoberto por Robert Koch em 1882 e, em 1890, o proprio Koch, a partir de cultivos de Mycobacterium tuberculosis, realizou as primeiras tentativas para combater essa afecção. O cultivo era filtrado e concentrado por evaporação, o qual foi denominado tuberculina de Koch (BIER, 1985).

Entre muitas tentativas para obter uma vacina contra a tuberculose está a de Cavagnis, em 1886(PUGA, 1986), o qual tentou imunizar pacientes tuberculosos com bacilos "vivos" provenientes de escarros bacilíferos tratados com fenol, obtendo resultados negativos.

Em 1894, Calmette foi encarregado por Roux para criar em Lille, França, uma filial do Instituto Pasteur. Foi desta maneira que, vivendo em contato com uma população onde as condiçōes de vida eram precárias e onde a tuberculose causava grande mortalidade, Calmette decidiu dedicar-se ao estudo dessa doença e, especialmente, em descobrir uma vacina que pudesse, um dia, imunizar as pessoas contra a tuberculose (BRETEY, 1971).

Em 1902, Nocard isolou uma cepa altamente virulenta do leite de bovinos infectados com o bacilo da tuberculose (BRETEY, 1971). Em 1908, Calmette e Guérin receberam a cepa virulenta de Mycobacterium bovis isolada por Nocard (GHEORGHIU et alii, 1983) e, a partir desta cepa, depois de 12 anos (1908 a 1920) e 230 passagens sucessivas do bacilo, obtiveram uma cepa avirulenta, cultivada em batata biliada glicerinada (CALMETTE et alii, 1921), a qual foi testada em animais de laboratório.

Os estudos de Calmette e Guérin foram de fundamental importância em Saúde Pública para o controle da tuberculose.

O programa de controle da tuberculose, segundo a ORGANIZAÇĀO PANAMERICANA DE SAÚDE (OPS, 1987), abrange três atividades principais: a vacina- 
ção com BCG, a quimioprofilaxia e a deteç̧ão de casos seguida de tratamento curativo.

$A$ vacinação com $B C G$ tem sido um dos componentes mais importantes de controle da tuberculose. Ela consiste em substituir a infeç̧ão natural virulenta por outra avirulenta.

A obtenção de um efeito protetor completo exige um agente potente e a adoção de uma técnica adequada de vacinação. O sucesso da vacinação, por sua vez, dependerá do tipo de cepa utilizada, da massa bacteriana total e da proporçāo de partículas viáveis da vacina. No momento de sụa aplicação devem ser também considerados a preservação contra danos ocasionados pela luz ou pelo calor, o prazo de expiração e a dose que se injeta (OPS, 1987; ten DAM, 1984).

Nos últimos 25 anos, muitos pesquisadores se direcionaram para o desenvolvimento de métodos e testes de controle de qualidade da vacina. Um importante avanço foi a introduçāo, pela OMS, em 1966, dos requisitos para a vacina BCG liofilizada (WHO - no 638). Posteriores progressos neste campo foram feitos pelo "establishment of the WHO -sponsored international quality control of B.C.G." (WHO/TB/Technical guide/77.8.), assim como pela distribuiçāo do "TECHNICAL Guide for in vitro assays of BCG products, revised" (WHO/TB Technical Guide/77.9.).

Entretanto, sempre se considerou importante (ENGIBAROV et alii, 1986) a busca de métodos adequados para a determinação mais rápida e acurada da viabilidade da vacina $B C G$, por um equipamento de fácil manejo.

A viabilidade, ou seja, a relação entre bacilos vivos e mortos é um importante determinante das características de uma vacina. A proporção global de bacilos (massa bacteriana total), é estimada pelo peso seco e/ou pela opacidade, e a proporção de bacilos vivos pela contagem de partículas cultiváveis (WHO/TB/77.9).

A obtenção de uma vacinação eficaz depende de um controle de viabilidade adequado da vacina. Sabe-se que uma vacina de boa qualidade deverá conter a máxima proporção possível de bacilos vivos que determinariam, conseqüentemente, maior sensibilidade à tuberculina e maior grau de proteção.

Foi somente a partir de 1948, que a Organização Mundial de Saúde assumiu a responsabilidade pelo controle de qualidade da vacina BCG. Desde entāo, esse 
sistema vem sofrendo mudanças tanto nos métodos de produção como nos testes de controle de qualidade (MILSTIEN \& GIBSON, 1990).

Em 1974, a "Twenty - Seventh World Health Assembly" reafirmou a importância do controle de qualidade da vacina BCG e recomendou que todos os países membros, produtores ou importadores, adotassem o sistema internacional da OMS, até terem um serviço de controle de qualidade competente (MILSTIEN \& GIBSON, 1990).

Várias provas têm sido desenvolvidas para a determinação da viabilidade da vacina $\mathrm{BCG}$, mencionado-se, dentre elas, a medida da capacidade de germinação, a determinaçāo do número de partículas cultiváveis, a dosagem de adenosina trifosfato (ATP) e a determinação do consumo de oxigênio.

A determinação da taxa de germinação - método de ORSKOV \& ENGBAEK, 1952 e ENGBAEK \& ORSKOV, 1952 - é uma prova de viabilidade que permite obter informação sobre a proporçāo de organismos viáveis e mortos e não sobre o número de organismos viáveis. Trata-se de uma prova não paramétrica que, além de tudo, é de difícil execução (WHO/TB/77.8).

A determinação de partículas cultiváveis é a prova de viabilidade capaz de dar informaçōes mais fidedignas. E um método utilizado em todos os laboratórios especializados em controle de qualidade e na maioria dos centros de produção de vacina BCG. Esta prova, cujo resultado é obtido após 28 dias, consiste na verificação do número de unidades formadoras de colônias (UFC) de BCG por mililitro (mL) da vacina reconstituída. Apesar de ser o mais informativo teste de viabilidade, está ele sujeito a considerável variabilidade, já que depende do meio da cultura utilizado, dos seus componentes e do procedimento do teste, que induzem a erros quando se comparam diversas vacinas.

O conteúdo em ATP, medido pela técnica de bioluminescência mostra-se proporcional à viabilidade da vacina $B C G$ e é, assim, um seguro marcador de células vivas (GHEORGHIU \& LAGRANDERIE, 1979 ; GHEORGHIU et alii, 1984). Trata-se, no entanto, de um método que requer enzimas especiais e equipamento parc medida de bioluminescência, ambos de custo elevado. Por outro lado, um complicados técnico na utilização da dosagem de ATP, para o estudo da viabilidade do BCG consiste em estimar o conteúdo do ATP por partícula cultivável para uma dada cepi da vacina. 
A determinação do consumo de oxigênio executada em respirômetro de Warburg (BUNCH - CHRISTENSEN, 1971), de uso generalizado, nåo $€$ adequado como prova de rotina para as variações entre lotes de produtos liofilizados por necessitar de um grande número de ampolas (30 a 120mg de peso semi-seco nominal para cada determinação), além de exigir medidas sempre em duplicatas (WHO/TB/77.8 ; WHO/TB/77.9).

É preciso ressaltar, porém, que os métodos anteriormente indicados, utilizados na determinação da viabilidade, só são empregados durante o controle do processo de produção e antes da liberação dos lotes de vacinas. Um aspecto importante que deve, entretanto, ser ressaltadoé que as unidades de saúde, do modo como o sistema está estruturado a nível mundial, não possuem capacidade técnica, por falta de um teste adequado, para avaliar a viabilidade dos lotes de vacina na etapa de pré-imunização.

No Brasil , a vacina BCG liofilizada é produzida pelo Instituto Butantan, de São Paulo e pela Fundação Ataulpho de Paiva, do Rio de Janeiro. Em razão das grandes distâncias e da precariedade de transporte em algumas áreas, a verificaçāo da viabilidade da vacina nas diversas regiōes brasileiras torna-se praticamente inviável. Por outro lado, outro problema que se justapōe é o das variações de temperatura nas diferentes regiōes do país e de problemas ligados à manutenção de vacina que interferem em sua viabilidade.

Atualmente, existe um melhor treinamento do pessoal de enfermagem para a manutenção da vacina BCG liofilizada nas unidades de saúde brasileira (BRASIL, MINISTÉRIO DA SAÚDE, 1979; SĀO PAULO, SECRETARIA DE ESTADO DA SAÚDE DE SĀOPAULO, 1988). Contudo, em situações onde ocorre falta de energia elétrica, as vacinas poderāo sofrer alteraçōes dos valores especificados de suas unidades viáveis, na medida em que a temperatura se eleva, resultando em perda de potência que é cumulativa e proporcional ao tempo de exposiçāo ao calor (OPS, 1979; OPS 1987; WHO, 75.101).

Com relação à exposiçāo à luz solar tropical, 5 minutos são suficientes para reduzir o número de partículas cultiváveis a 50\%( OPS, 1987). Em 60 minutos, a redução pode atingir $99 \%$ (OPS, 1979). Assim, a incidência da luz solar $\varepsilon$ crucial para a viabilidade da vacina (ten DAM, 1984). A luz indireta por 15 minutos, promove tambem uma perda de 50\% a 90\% (OPS, 1987; ten DAM, 1984). 
Considerando as dimensōes continentais do Brasil , a diversidade de clima e mesmo a incidência de luz solar, além das condiçōes de trabalho peculiares às suas diversas regiōes, deve-se considerar a possibilidade de utilização de um método de rápida execução, confiável e capaz de proporcionar dados reprodutíveis que permitam determinar com rapidez e segurança as condiçōes da vacina BCG, no momento de sua aplicação. Para tal finalidade, a conduta mais recomendável será a de determinar a viabilidade da vacina em termos de consumo de oxigênio. Entretanto, pelas suas características, a respirometria pela técnica tradicional de Warburg, mostra-se impraticável.

Dos métodos correntes utilizados na medida do oxigênio e do seu consumo por sistemas biológicos, um dos mais sensíveis é o polarográfico. Ademais, esse método apresenta excelentes características por ser de rápida execução e de boa confiabilidade e reprodutibilidade (LUCCHIARI, 1978; LUCCHIARI \& HOSHINO, 1980).

O método polarográfico vem sendo amplamente utilizado, de longa data, para a determinaçāo do consumo de oxigênio em diferentes situações experimentais, tais como no estudo da respiração de algas (PETERING \& DANIELS, 1938); na respiração de leveduras (BAUMBERGER, 1939); para a determinaçảo do consumo de oxigênio e taxa de consumo de oxigênio em meios de cultivo bacteriano (SKERMAN \& MILLIS, 1949); na determinaçāo da fosforilação oxidativa de mitocôndria isolada (CHANCE \& WILLIAMS, 1955); no estudo do metabolismo de microorganismos (BACILA, 1959); na determinação da atividade da galactose oxidase (AMARAL \& BACILA, 1967); em diversos modelos para o estudo da respiração mitocondrial (VOSS et alii, 1963; BACILA \& VOSS, 1967; BACILA et alii, 1989); e, ainda, em diversos modelos biológicos "in vivo" (DAVIES \& BRINK, 1942: MEDINA et alii, 1967; LUCCHIARI ,1978; LUCCHIARI \& HOSHINO, 1980; LUCCHIARI et alii, 1984; SAKATE et alii, 1987; CICOGNA et alii, 1988; LUCCHIARI et alii, 1989).

Mesmo que essa metodologia possa ter significado regional no controle da vacina que está sendo utilizada na imunizaçāo contra a tuberculose, certamente o emprego do método polarográfico poderá ter significado muito maior na sua padronização, no controle de qualidade da vacina durante a sua produção e nos procedimentos que antecederiam a vacinação.

A razāo disso reside no fato de que a clássica técnica de Warburg, utilizada para monitorizar a produção da vacina $\mathrm{BCG}$, é um método semi-analítico que exige grandes quantidades de vacina líquida ou liofilizada para proporcionar leituras de 
consumo de oxigénio mensuráveis, enquanto que o método polarográfico, muito mais sensivel e de execução simples exige quantidades bem menores de material a ser medido (MALUCELLI et alii, 1990 a, b.). Por outro lado, o tempo de execução de uma medida polarográfica de consumo de oxigênio é bem inferior ao que deve ser empregado na respirometria a Warburg o que indica, também, a possibilidade de seu emprego para monitorizar o processo de preparação da vacina BCG.

Tendo em vista a necessidade de que a viabilidade da vacina $B C G$ seja testada a nivel de Unidades de Saúde, acredita-se que o método polarográfico poderá atender à solicitação da OMS (ENGIBAROV et alii, 1986; MILSTIEN \& GIBSON, 1990) para a busca de uma metodologia mais adequada que possa ser empregada na determinação da viabilidade da vacina $\mathrm{BCG}$ e no controle de processo durante sua fabricaçāo. 


\section{2 - OBJETIVOS}

\section{1 - Objetivo Geral:}

2.1.1 - Avaliar a possibilidade da utilização do método polarográfico, na determinação da viabilidade da vacina $B C G$ liofilizada.

\section{2 - Objetivos Específicos:}

2.2.1 - Determinar o consumo de oxigênio pelo método polarográfico, utilizando amostras de vacina BCG liofilizada: em diferentes concentrações bacilares, em diversas temperaturas e empregando-se diferentes diluentes.

2.2.2 - Comparar os resultados do método polarográfico, do método respirométrico de Warburg e da contagem de colônias, na determinação da viabilidade da vacina BCG liofilizada, utilizando "pool" de amostras.

2.2.3 - Comparar os resultados do método polarográfico na determinação da viabilidade da vacina BCG liofilizada, com o método de Warburg e com o da contagem de colônias, realizadas pelo controle de qualidade do Instituto Butantan.

2.2.4 - Avaliar a reprodutibilidade do método polarográfico em diferentes lotes da vacina. 


\section{3- MATERIAL E METODOS}

\section{1 - AMOSTRAS DE VACINA BCG LIOFILIZADA PARA A DETERMINAÇĀO DA VIABILIDADE。}

Foram utilizadas as seguintes vacinas:

3.1.1 - Vacina BCG liofilizada produzida, tanto pelo Laboratório de Vacina BCG Intradérmica do Instituto Butantan (São Paulo), como também pela Fundação Ataulpho de Paiva (Rio de Janeiro) foram utilizadas para determinação de viabilidade. A produção dessas vacinas obedeceram às Normas de Produção preconizadas pela Organizaçāo Mundial da Saúde (WHO, n638, 1979; WHO/BLG/UNDP/82.1 ; OMS, 1987).

3.1.2 - Vacina BCG liofilizada de Referência Nacional, cepa Moreau, do Instituto Nacional de Controle de Qualidade em Saúde (INCQS), com as codificaçōes $\mathrm{BRA} / \mathrm{BCG} / 000$ e BRA/BCG/001, foi utilizada para a determinação em paralelo do Número de Unidades Formadoras de Colônias (UFC).

\section{2 - TÉCNICAS EMPREGADAS PARA A DETERMINAÇĀO DA VIABILIDADE DA VACINA BCG LIOFILIZADA.}

3.2.1 - Determinação do Número de Unidades Formadoras de Colônias (UFC), pelo Método de Contagem de Colônias.

A determinação do Número de Unidades Formadoras de Colônias consiste na verificaçāo do número de unidades de Mycobacterium bovis viáveis por mililitro da vacina, reconstituída em meio diluente Sauton - água, na proporção 1:4 (1+3). A contagem de colônias foi realizada após 28 dias de cultivo a $37^{\circ} \mathrm{C}$ em meio de Lowenstein - Jensen.

Para esta determinaçāo, seguiu-se o procedimento recomendado pela OMS (WHO/TB/77.9) em que se utiliza uma série única de três diluiçōes (relação 1:2:4) a qual foi semeada em cinco tubos contendo meio de Lowenstein - Jensen para as diluiçōes mais concentradas e dez para as mais diluídas (série 5, 5 e 10). A confiabili- 
dade do experimento foi controlada por análise estatistica, sendo que a significância da variaçāo do número de colónias por tubo inoculado com uma mesma diluição foi avaliada pela prova do Qui-quadrado $\left(x^{2}\right)$ e para a significancia das diferenças entre as médias obtidas para diluiçōes consecutivas, utilizou-se o teste " $t$ " de Student. A estimativa baseou-se em um número ótimo de colónias $(\omega=40)$.

Em paralelo às determinaçōes, utilizou-se uma Vacina de Referência Nacional.

3.2.2 - Determinaçāo do Consumo de Oxigênio pelo Método Respirométrico de Warburg.

A clássica técnica respirométrica de Warburg que baseia-se na medida da variação de pressão em um sistema fechado, provocada pela variação na quantidade de gás resultante de atividade metabólica, à temperatura constante, está descrita em detalhes nas publicaçōes de SLATER (1967), VILLELA et alii (1973) e OMS (1987). Em resumo, após o ajuste da temperatura do aparelho de Warburg (BRAUN -MELSUNGEN - Modelo V-166), a $37^{\circ} \mathrm{C}$, colocou-se uma tira de papel de filtro sanfonado ( $30 \times 6 \mathrm{~mm})$ no poço central de cada frasco de reação e adicionou-se $0,2 \mathrm{~mL}$ de solução de hidróxido de potássio a $20 \%$. Este procedimento foi necessário a fim de absorver o gás carbônico produzido, permitindo, desta maneira, a medida da variaçāo de pressão decorrente do consumo de oxigênio.

O conteúdo de ampolas de vacina BCG liofilizada foi reconstituído em soluçāo fisiológica tamponada ou em soluçāo de glutamato de sódio a 2,0\% de maneira a conter $10 \mathrm{mg}$ de vacina por $\mathrm{mL}$. Desta preparação foram adicionados no frasco de reação $2,8 \mathrm{~mL}$ do diluente contendo $30 \mathrm{mg}$ de $\mathrm{BCG}$. O frasco de reaçāo foi fixado no manômetro e as juntas esmerilhadas foram convenientemente lubrificadas com vaselina de silicone. $\mathrm{O}$ conjunto foi, então, colocado em banho maria a $37^{\circ} \mathrm{C}$ sob agitaçāo constante, por 15 minutos, para equilibrar a temperatura, com o sistema aberto.

Após oclusão do sistema, a coluna manométrica da direita foi ajustada em $150 \mathrm{~mm}$, procedendo-se a leitura inicial na coluna da esquerda (tempo zero) e as leituras subseqüentes efetuadas a intervalos de 30 minutos durante 2 horas.

Para corrigir variaçōes do ambiente foi utilizado um frasco adicional, como termobarômetro, contendo apenas água. Qualquer variaçāo nesse sistema é proveniente apenas de alteraçōes na pressāo atmosférica ou na temperatura do banho. Essas 
variações foram anotadas no momento das leituras e utilizadas para correções posteriores.

Sabendo-se a quantidade de oxigênio consumido e a quantidade de material biológico presente no sistema, calculou-se o coeficiente metabólico $\mathrm{QO}_{2}$, que representou a taxa de consumo de oxigênio por unidade de material biológico. Para o caso da medida de consumo de oxigênio pela vacina BCG liofilizada, utilizou-se a seguinte expressão:

$$
\mathrm{QO}_{2}=\frac{\text { soma das leituras corrigidas }}{\text { concentração da vacina } \times \mathbf{n}^{\mathbf{Q}} \text { de horas }}
$$

portanto $\mathrm{QO}_{2}=\mu \mathrm{L}$ de oxigênio consumido/mg da vacina/hora

$$
\mathrm{QO}_{2}=\mu \mathrm{LO} / \mathrm{mg} / \mathrm{h}
$$

Para facilitar a comparação entre os resultados obtidos no respirômetro de Warburg com os do método polarográfico converteu-se a unidade $\mu \mathrm{LO}_{2} / \mathrm{mg} / \mathrm{h}$ em $\mathrm{m} u \mathrm{MO} 2 / \mathrm{s}$ para $10 \mathrm{mg}$ de pó vacinal, multiplicando-se o valor obtido na respirometria a Warburg $\mu \mathrm{LO} 2 / \mathrm{mg} / \mathrm{h}$ por 0,124 , obtido da expressāo:

$$
C=\frac{10}{3.600 \times 0.0224}=0,124
$$

onde: $1 \mathrm{~m} \mu \mathrm{MO}_{2}$ equivale a $0,0224 \mu \mathrm{L}$ de $\mathrm{O}_{2}$ e 1 hora $=3.600 \mathrm{~s}$.

3.2.3 - Determinação do Consumo de Oxigênio pelo Método Polarográfico.

\subsubsection{1 - Princípio do método}

A medida polarográfica da concentração de oxigênio dissolvido numa solução consiste na medida da corrente elétrica que circula entre dois eletrodos, um de platina (cátodo) e outro de referência (ânodo), quando submetidos a uma diferença de potencial elétrico. Geralmente é utilizado prata-cloreto de prata como eletrodo de referência (FIGURA1). 


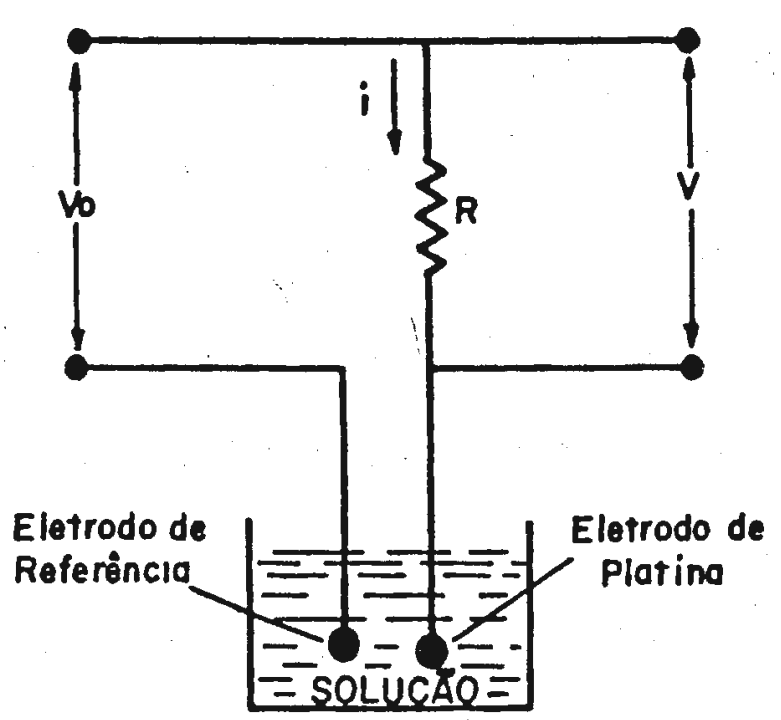

FIGURA 1 - Representação esquemática do circuito para medida polarográfica da concentração de oxigênio. $V_{0}$ - voltagem de polarização; i - corrente de polarização; V- diferença de potencial num resistor $R$.

A FIGURA 1 ilustra esquematicamente o circuito utilizado na medida polarográfica. Dependendo da geometria adotada na construção do eletrodo de platina, a diferença de potencial $V_{0}$ aplicada entre os eletrodos pode variar entre 0,5 e $0,9 \mathrm{~V}$ e demonina-se voltagem de polarização. A corrente i que circula entre os eletrodos, como conseqüência da aplicação da voltagem de polarização, denomina-se corrente de polarização e é medida pela queda de tensão num resistor $\mathbf{R}$ associado em série com os eletrodos.

Sob o aspecto físico-químico, estando o eletrodo de platina a um potencial negativo, ele fornece elétrons que participam das reaçōes na sua superfície. De acordo com HANN et alii ( 1975), o oxigênio na superfície da platina é reduzido segundo as equações:

$$
\begin{aligned}
& \mathrm{O}_{2}+\mathrm{H}_{2} \mathrm{O}+\mathrm{e}^{-} \rightleftharpoons \mathrm{HO}_{2}^{-}+\mathrm{OH}^{-} \\
& \mathrm{HO}_{2}^{-}+\mathrm{H}_{2} \mathrm{O}+2 \mathrm{e}^{-} \longrightarrow 3 \mathrm{OH}^{-}
\end{aligned}
$$

A primeira equação é válida para soluções com pH maior do que 8 ou 9, enquanto a segunda ocorre em potenciais mais negativos do que a primeira.

As reaçōes mostram haver na superfície da platina um consumo de oxigênio diretamente proporcional ao número de elétrons fornecidos e, portanto, diretamente proporcional à corrente de polarização. 
À medida que o oxigénio é consumido na superfície da platina, mais moléculas da massa líquida ambiental, por difusão, chegam ao eletrodo e assim dando continuidade à reaçāo. Desta maneira, a agitaçāo da solução favorece a chegada do oxigênio na superfície do eletrodo.

O processo físico-químico pode ser dividido em três etapas fundamentais:

a- quando a voltagem de polarizaçāo está situada entre aproximadamente $0 \mathrm{~V}$ e $0,5 \mathrm{~V}$, o oxigênio existente na superfície da platina é suficiente para reagir com todos os elétrons fornecidos. A corrente de polarização aumenta quando a voltagem de polarização aumenta de $0 \mathrm{~V}$ até $0,5 \mathrm{~V}$;

b- entre aproximadamente $0,5 \mathrm{~V}$ e $1,0 \mathrm{~V}$, o número de elétrons fornecidos $\varepsilon$ suficiente para reagir com todo o oxigênio na superfície da platina. A corrente de polarizaçāo torna-se praticamente independente da voltagem de polarizaçāo e passa a depender do coeficiente de difusão do oxigênio na solução;

c- para as voltagens acima de $1,0 \mathrm{~V}$ a corrente de polarização aumenta abruptamente devido a redução direta dos íons $\mathrm{H}^{+}$.

Portanto, normalmente, as medidas de concentração de oxigênio são feitas usando voltagem de polarizaçāo entre $0,5 \mathrm{~V}$ e $1,0 \mathrm{~V}$ e no presente trabalho a voltagem de polarização foi fixada em $0,6 \mathrm{~V}$.

Diante do exposto, torna-se compreensível que para uma solução em repouso, ou uniformemente agitada, a corrente de polarizaçāo dependerá dos seguintes fatores:

- área da superfície da platina em contato com a soluçāo;

- solubilidade do oxigênio da solução;

- coeficiente de difusão do oxigênio na solução;

- temperatura da solução;

- concentraçāo do oxigênio na soluçāo.

Tornando-se constante a temperatura para um mesmo par de eletrodos, numa solução uniformemente agitada, a corrente de polarização passa a depender única e linearmente da concentração do oxigênio. Desta forma, torna-se possivel determinar a concentração de oxigênio, conhecendo-se apenas a corrente de polarização. 


\subsubsection{2 - Circuito Polarográfico.}

Trata-se do circuito eletrônico que deve fornecer a voltagem de polarização ao eletrodo e ampliar a corrente de polarização a níveis compatíveis com o sistema de registro utilizado. $O$ circuito empregado neste trabalho foi o descrito por LUCCHIARI et alii, 1984.

\subsubsection{3 - Termômetro Digital.}

Para a medida da temperatura, simultaneamente com a do consumo de oxigênio, adotou-se com modificaçōes, o circuito publicado por DEWHURST (1976) em que o termistor no interior do eletrodo conjugado foi conectado a um circuito em ponte de Wheatstone; substituiu-se o microamperímetro para indicação da temperatura (escala analógica) por um DPM (display panel meter) de 3 dígitos com precisão de leitura de $0,1^{\circ} \mathrm{C}$, providos também com saída para registrador.

\subsubsection{4 - Agitador Magnético.}

$\mathrm{O}$ agitador magnético foi construído utilizando um micro motor marca "Oxford" de $2.000 \mathrm{rpm}$ e $9 \mathrm{~V}$ de alimentaçāo. A polia do motor, medindo 6,2 milímetros de diâmetro, aciona outra de 44 milímetros de diâmetro, através de uma correia de borracha. Sobre a polia maior foi fixado um ímã medindo $24 \times 14 \times 6$ milímetros. Esta montagem permite ao ímã girar a $280 \mathrm{rpm}$, velocidade suficiente para arrastar a barra magnética no interior da câmara de reaçāo e provocar agitaçāo uniforme do meio líquido, sem provocar turbilhonamento.

\subsubsection{5 - Polarógrafo.}

O circuito polarográfico com o termômetro digital e suas respectivas fontes de alimentação foram montadas em um chassi de alumínio, medindo $21 \mathrm{~cm}$ de largura e $11 \mathrm{~cm}$ de altura. Para facilidade de manuseio do equipamento, o agitador magnético foi fixado no lado interno da tampa superior do chassi. $O$ conjunto assim montado foi denominado simplesmente de polarógrafo. 


\subsubsection{6 - Sensor - Eletrodo Combinado para Oxigênio e Temperatura.}

O eletrodo para medida do oxigênio foi construído, basicamente, de acordo com MICKEL et alii, 1983, com a inclusão no seu interior de um termistor para indicar a temperatura durante a medida de concentração de oxigênio (FIGURA 2), fixando-o bem próximo da superfície de platina.

Para a construção do eletrodo, um fio de platina de $0,5 \mathrm{~mm}$ de diâmetro foi inclurdo numa das extremidades de um tubo de vidro mole de $4 \mathrm{~mm}$ de diâmetro externo. Um anel de prata $(99,95 \%$ pura) foi fixado envolvendo a extremidade do vidro onde a platina estava incluída. Imediatamente acima do anel de prata, numa escarificação feita na parede do tubo de vidro, foi fixado um termistor de $20 \mathrm{k}$ de resistência e coeficiente de variação térmica $4000 \mathrm{~K}$. Ao fio de platina e ao anel de prata foram soldados fios de cobre para contato com o exterior. $O$ conjunto foi cimentato com resina Epoxi (The Dextor Corporation) no interior de um tubo de acrílico. Após o endurecimento da resina, o eletrodo foi polido cuidadosamente em suas faces externas, primeiro com lixa d'água número 600 e depois com flanela.

Finalmente, uma membrana de diálise (Dyalysis "Sacks" - Sigma) foi amarrada, com fio de "nylon" fino, num sulco próximo da extremidade inferior do eletrodo, recobrindo totalmente as superfícies da prata e da platina, expostas ao exterior. Esta membrana visa impedir o depósito de proteínas na superfície da platina, provocada pela passagem da corrente elétrica, tornando o eletrodo mais estável e prolongando sua vida útil.

Dentre as diferentes nomenclaturas usadas para a denominaçāo dos sensores para medida da concentração do oxigênio, citamos: eletrodo para oxigênio (COBBOLD, 1974); cátodo para oxigênio (DAVIES, 1962); sensor polarográfico para oxigênio (FATT, 1976). 


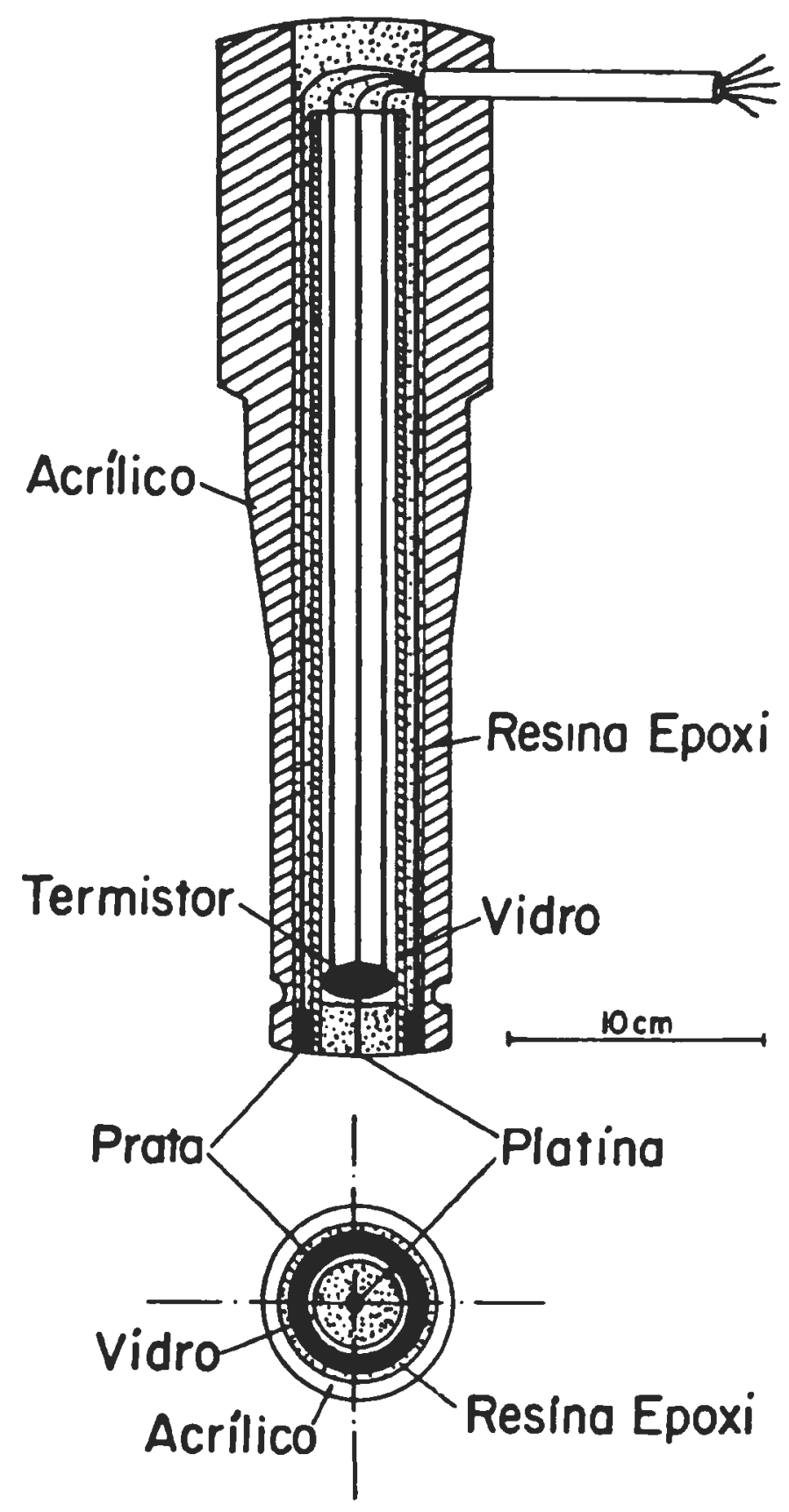

FIGURA 2 - Representação do eletrodo combinado para oxigênio e temperatura. Corte feito no mesmo plano do eixo do eletrodo.

\subsubsection{7 - Câmara de Reação.}

Baseada em LUCCHIARI (1978) a câmara de reaçāo para estudo da determinaçāo do consumo de oxigênio da vacina $B C G$, foi construída em acrílico, substituindo-se os eletrodos separados de platina e prata- cloreto de prata, pelo eletrodo combinado, descrito no item 3.2.3.6.

A FIGURA 3 representa esquematicamente a cuba de reação, através de um corte no mesmo plano de seu eixo, sendo composta de uma cámara cilíndrica, medindo 
$1,5 \mathrm{~cm}$ de diâmetro por $2,0 \mathrm{~cm}$ de altura e fixada no interior de uma cuba, também de acrńlico, formando um conjunto único, denominado corpo da cuba (G). A tampa $H$, fixa-se por parafusos ao corpo da cuba. Dois aneis de borracha (I) foram colocados entre a tampa e o corpo para previnir vazamento de água. A entrada (A) e a saída (B) foram interligadas a um banho maria com circulação de água, permitindo controlar a temperatura no interior da câmara. Pela abertura (E) na tampa da cuba o eletrodo combinado (sensor) foi introduzido na câmara ficando sua extremidade a 5 milímetros da base da câmara, sendo que o eletrodo veda completamente a abertura (E). O meio líquido no interior da câmara foi mantido sob agitação uniforme através da barra magnética (C), acionada por um agitador, sobre o qual fica apoiada a cuba. A abertura (F) permite, com auxílio de uma seringa "tipo tuberculina", introduzir material no interior da câmara, mesmo durante as medidas. $O$ esvaziamento da câmara foi feito através da saída (D), pela aspiraçāo com uma trompa d'água.



FIGURA 3 - Representação esquemática da cuba de reação utilizada na determinação do consumo de oxigênio da vacina BCG liofilizada. A e B - entrada e saída de água para manutenção de temperatura constante; $\mathrm{C}$ - barra magnetıca para homogeneização; D - saída para limpeza da câmara de reação por sucção com uma trompa d'agua; E - abertura para colocação do sensor polarográfico; F orifício para introdução de material na câmara de reação; $G$ - corpo da cuba; H - tampa da cuba; I - anéis de borracha para vedação.; J - câmara de reação.

\subsubsection{8 - Arranjo Experimental.}

O arranjo geral experimental como indicado na FIGURA 4 constou da: 
- introdução do eletrodo combinado na câmara de reação e sua conexăo ao polarógrafo.

- conexão das saídas do polarógrafo (oxigênio e temperatura) às entradas do registrador de dois canais (ECB - RB 202), ajustado para velocidade do papel $20 \mathrm{~cm} / \mathrm{h}$.

- ligaçāo da saída de escoamento da câmara de reação a uma trompa d'água.

- ligação da entrada e da saída da cuba a um banho maria com circulação (FABBE - 269), ajustado para que a temperatura no interior da câmara de reaçāo fosse $37^{\circ} \mathrm{C}$.

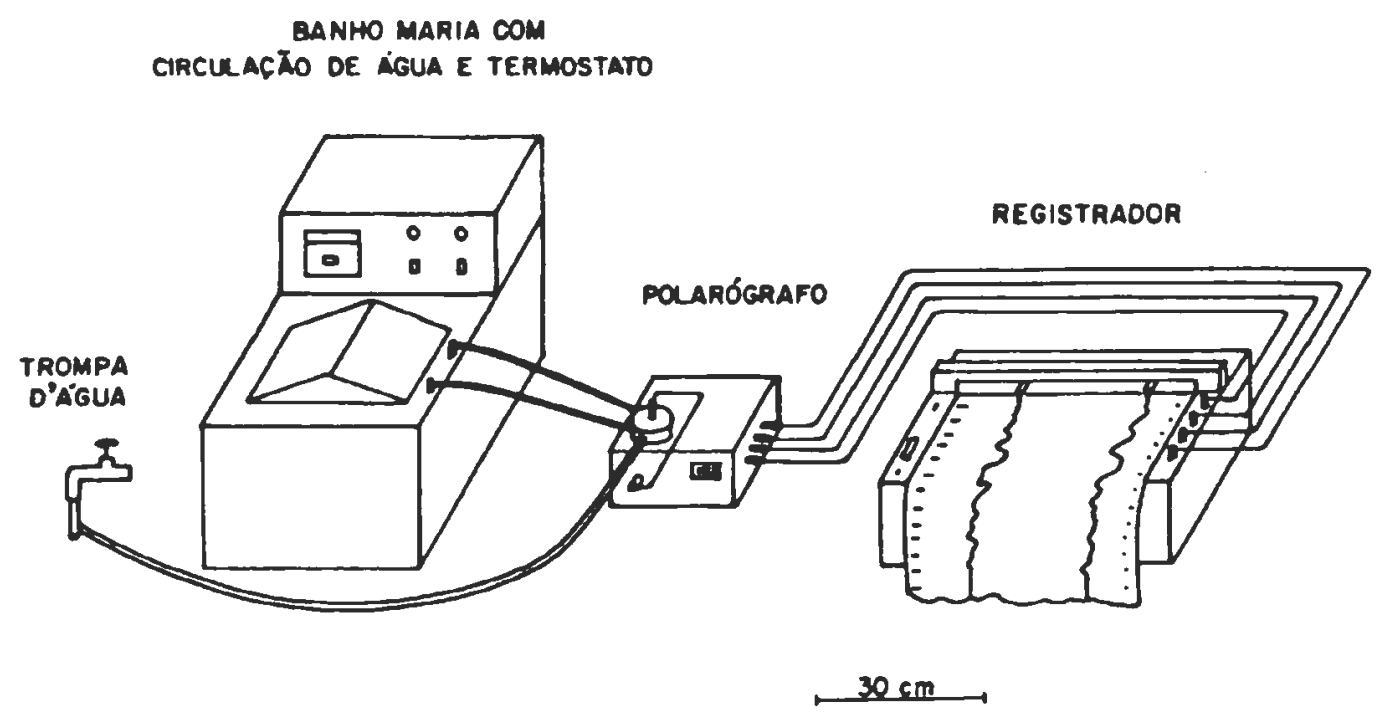

FIGURA 4 - Representação esquemática do arranjo geral experimental para determinação do consumo de oxigênio da vacina BCG liofilizada.

3.2.3.9 - Procedimento na Determinação do Consumo de Oxigênio da Vacina BCG Liofilizada.

3.2.3.9.1 - Limpeza e Desinfeç̧ão da Câmara.

Antes do início de cada determinação, lavou-se a câmara com detergente neutro (Extran 3\%), sob agitação, seguida de 3 passagens de água destilada. A câmara 
foi desinfetada com álcool a $70^{\circ} \mathrm{GL}$ durante 15 minutos. Esvaziou-se o recipiente e lavou-se novamente três vezes com água destilada estéril.

Após o término das determinações do consumo de oxigênio, colocou-se na câmara soluçāo de hipoclorito de sódio a $10 \%$ e procedeu-se a lavagem.

\subsubsection{2 - Estabilização do sistema.}

Após limpeza e desinfeç̧ão, que foi efetuada ao início de cada determinação diária, lavou-se a câmara com solução fisiológica tamponada estéril $(\mathrm{NaCl}=6,8 \mathrm{~g}$; $\mathrm{Na}_{2} \mathrm{HPO}_{4}=1,48 \mathrm{~g} ; \mathrm{KH}_{2} \mathrm{PO}_{4}=0,43 \mathrm{~g} ; \mathrm{H}_{2} \mathrm{O}$ destilada q.s.p., $1000 \mathrm{~mL} ; \mathrm{pH}=6,8$; autoclavação $=120 \mathrm{C} \times 15 \mathrm{~min}$ ), com a finalidade de eliminar qualquer resíduo de água.

Adicionou-se 1,5 mL de solução fisiológica tamponada estéril, e colocou-se o sensor, previamente lavado, com a mesma solução, secando-o com papel absorvente estéril. Deixou-se 15 minutos para estabilização do sistema, com adequado equilíbrio da temperatura. Ligou-se o registrador e ajustou-se o sistema a $0 \% \mathrm{e} \mathrm{a} \mathrm{amplitude} \mathrm{para}$ $100 \%$ de saturação de oxigênio.

\subsubsection{3 - Reconstituição das Vacinas e Adição da Amostra.}

Os cuidados especiais com a abertura das ampolas obedeceram aos seguintes procedimentos: bateu-se levemente com a ampola sobre a mesa, para que o pó vacinal se depositasse no fundo; limpou-se o gargalo da ampola com uma gaze ou algodāo umedecido em álcool $70^{\circ} \mathrm{GL}$; serrou-se o gargalo da ampola, na base do colo, sem abrí-la; limpou-se, novamente, o gargalo da ampola com uma gaze ou algodão umedecido em álcool $70^{\circ} \mathrm{GL}$; após verificar se o gargalo da ampola estava seco, envolveu-se a ampola com o saco plástico que a acompanhava e quebrou-se o gargalo no ponto em que foi serrado; retirou-se o plástico lentamente, a fim de permitir que $o$ ar penetrasse gradualmente na ampola, pois a entrada brusca de ar no interior da ampola, fechada a vácuo, provocaria a saída do pó vacinal sob a forma de aerosol. Com uma seringa estéril, aspirou-se $0,5 \mathrm{~mL}$ de solução fisiológica tamponada estéril $(\mathrm{pH}=6,8)$, adicionada de $0,3 \%$ de Tween 80 e injetou-se lentamente pela parede da ampola contendo o pó vacinal, agitou-se por rotação suave, tendo o cuidado de não formar espuma, uma vez que o pó vacinal poderia ficar retido nas bolhas de ar; transferiu-se o conteúdo desta ampola para a segunda ampola com o mesmo procedimento; aspirou-se com a mesma seringa e injetou-se na câmara contendo $1,5 \mathrm{~mL}$ de soluçāo fisiológica tampo- 
nada a temperatura de $37^{\circ} \mathrm{C}$, pelo orif́cio capilar F (FIGURA 3), $0,5 \mathrm{~mL}$ da amostra (10 mg).

\subsubsection{4 - Registro e quantificação.}

A queda da corrente de polarização, devida ao consumo de oxigênio do meio de reaçāo, juntamente com a temperatura deste, foram registrados e pelos dados da calibraçāo, estabeleceu-se a relação entre a variação da concentraçāo do gás e o tempo correspondente.

Como indicado na FIGURA 5, logo após a adição da amostra de vacina BCG liofilizada, a curva representativa do consumo de oxigênio sofre uma queda inicial mais acentuada. Isso ocorre devido a dois fatores simultaneos: o primeiro, tem como causa a diluiçāo do oxigênio existente no meio de reação e, o segundo, deve-se a queda de temperatura, mostrada no traçado superior. Logo apos a temperatura no interior da câmara ter retornado ao seu valor inicial $37^{\circ} \mathrm{C}$, a corrente de polarização passa a cair linearmente em função do tempo.

Para calcular a velocidade de consumo de oxigênio, considerou-se, na região linear da curva, arbitrariamente, um segmento correspondente a uma queda na concentração do oxigênio e o respectivo tempo gasto. A velocidade de consumo de oxigênio foi calculada pelo quociente da quantidade de oxigênio consumida pelo tempo gasto.

Por outro lado, considerando-se que a solubilidade do oxigênio na água saturada com ar atmosférico a $37^{\circ} \mathrm{C}$, obtida por interpolação nas tabelas de SMITH (1974), é de 4,68mL/, que transformada em número de moles por litro de soluçāo é igual a $209 \mu \mathrm{MO}_{2} / \mathrm{L}$.

$$
\frac{4,68 \times 10^{-3}}{22,4 \times 10^{3}}=209 \mu \mathrm{MO} / \mathrm{L}
$$

Sendo Vf o volume em $\mathrm{mL}$ do fluido na câmara de reação, o número de moles de oxigênio disponível no início da reação será dado por: $209 \times 10^{-3} \times \mathrm{Vf} \mu \mathrm{MO}_{2}$, valor este que corresponde a $100 \%$ do oxigênio disponivel para a reaçāo e que graficamente corresponde à amplitude total A, possível de ser medida em centímetros no registro.

A quantidade de oxigênio consumida pela amostra, durante o período considerado, foi representada na FIGURA 5 pela letra q e é calculada por: 


$$
\frac{\mathrm{q}}{\mathrm{A}} \times 209 \times 10^{-3} \times \mathrm{Vr} \mu \mathrm{MO}
$$

A velocidade do papel de registro tendo sido ajustada para $20 \mathrm{~cm} / \mathrm{h}$, o tempo gasto no consumo desta quantidade de oxigênio, representado na FIGURA 5 por $t$, $́$ calculado, em segundos, por:

$$
\frac{3600 \times t}{20}=180 \times t
$$

Finalmente para o cálculo da velocidade de consumo de oxigênio, temos:

$$
\text { Veloc. Cons. de } \mathrm{O}_{2}=\frac{209 \times 10^{-3} \times \mathrm{Vf} \times \mathrm{q}}{180 \times \mathrm{A} \times \mathrm{t}}
$$

expresso em $\mu \mathrm{MO}_{2} / \mathrm{s}$

ou

$$
\text { Veloc. Cons. de } \mathrm{O}_{2}=1,161 \times \frac{\mathrm{V} \times \mathrm{q}}{\mathrm{A} \times \mathrm{t}}
$$

expresso em $\mathrm{m} \mu \mathrm{MO}_{2} / \mathrm{s}$

onde, Veloc. Cons. de $\mathrm{O}_{2}$ representa a velocidade de consumo de oxigênio ou simplesmente, consumo de oxigênio expresso em mu $\mathrm{MO}_{2} / \mathrm{s}$ e calculada para o total da amostra de BCG utilizada. Os parâmetros A, q, t sāo medidos no gráfico em centímetros.

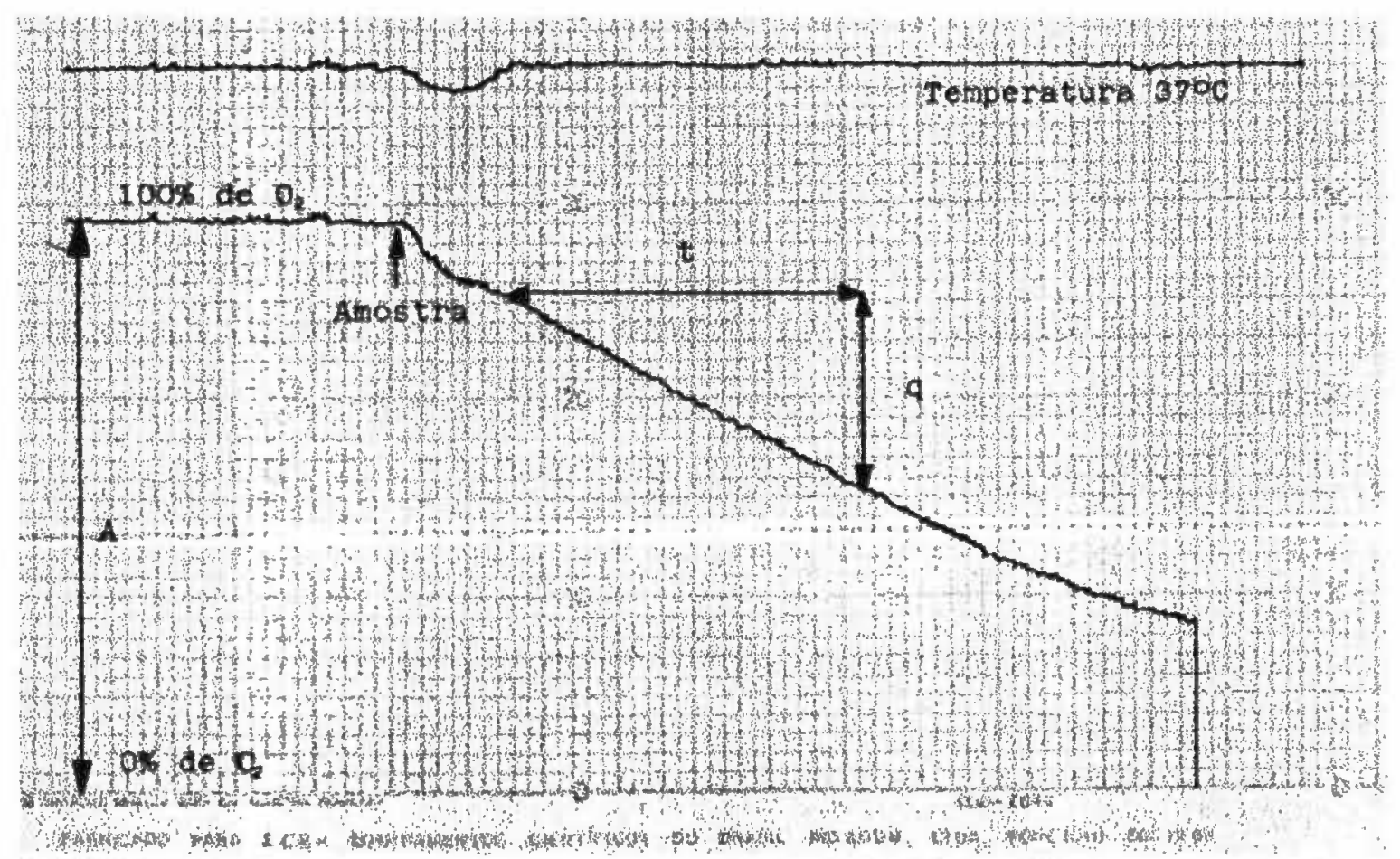

FIGURA 5 - Traçado experimental em registrador (ECB - RB 202), resultante da determinaçāo do consumo de oxigênio de $10 \mathrm{mg}$ da vacina BCG liofilizada, utilizando o método polarográfico descrito. 


\subsection{DELINEAMENTO EXPERIMENTAL}

Os seguintes experimentos foram realizados:

3.3.1 - Determinação do Consumo de Oxigênio pelo Método Polarográfico em Diferentes Cóncentraçōes de Vacina BCG Liofilizada.

Diferentes amostras de BCG nas concentrações de 1,2, 3, 5, 10, 20,50 e 100mg foram submetidas ao teste de consumo de oxigênio utilizando-se o método polarográfico, com a finalidade de testar a sensibilidade do método. Após o teste determinou-se a concentraçāo de proteína segundo a técnica descrita por LOWRY et alii (1951).

3.3.2 - Determinação do Consumo de Oxigênio, pelo Método Polarográfico, de Três Lotes da Vacina BCG Liofilizada, Submetida a Diferentes Temperaturas.

Este experimento foi realizado com o objetivo de testar a viabilidade das amostra submetidas às temperaturas de $42^{\circ} \mathrm{C}, 56^{\circ} \mathrm{C}, 70^{\circ} \mathrm{Ce} 100^{\circ} \mathrm{C}$, para verificação da confiabilidade do método polarográfico na medida de atividade respirométrica do BCG.

3.3.3 - Teste de Diferentes Diluentes para a Reconstituição da Vacina BCG Liofilizada.

Foram testados vários diluentes para a reconstituição da vacina, visando estudar o seu efeito na atividade respiratória da mesma. Utilizou-se para os testes, os seguintes diluentes: meio de Sauton (1:4), solução glutamato de sódio a $2 \%$, solução fisiológica tamponada, solução fisiológica tamponada adicionada de $0,1 \%, 0,2 \%$ ou $0,3 \%$ de Tween 80 .

3.3.4 - Estudo Comparativo da Viabilidade da Vacina BCG Liofilizada pelo Método Polarográfico, pela Técnica Respirométrica de Warburg e pela Contagem de Colônias.

33.4.1 - Com a finalidade de comparar os diferentes métodos para a determinação da viabilidade da Vacina BCG liofilizada foi utilizado "pool" de amostras da vacina do Instituto Butantan e também da Fundação Ataulpho de Paiva. 
Foram realizados 20 experimentos com vacinas, constitufndo-se cada um deles em "pool" diferentes, sendo que para cada experimento foi utilizado um "pool" de vacinas em solução fisiológica tamponada e dividido conforme as necessidades de cada método. As técnicas de determinação de viabilidade da vacina foram realizadas imediatamente após a reconstituição, visando utilizar a mesma amostragem.

33.4.2 - Trinta e três lotes de vacina BCG liofilizada originárias do Instituto Butantan estocadas após sua produção durante 30 dias à temperatura de 4 a $8^{\circ} \mathrm{C}$ e um lote de número 870724 produzida em 1987 pela Fundação Ataulpho de Paiva, mantida à mesma temperatura, foram reconstituídas em solução fisiológica tamponada adicionada de $0,3 \%$ de Tween 80 , e analisadas quanto ao consumo de oxigênio, pelo método polarografico. Os resultados obtidos pelo método polarográfico foram comparados com aqueles obtidos dos testes de controle de qualidade (viabilidade), realizados para a liberaçāo dos lotes (método respirométrico de Warburg e contagem de colônias).

\subsection{5 - Avaliação de Reprodutibilidade do Método Polarográfico em Diferentes Lotes de Vacina BCG Lionlizada.}

Foram realizadas 98 determinaçōes de consumo de oxigênio pelo método polarográfico, em 12 amostras provenientes do Instituto Butantan e da Fundação Ataulpho de Paiva.

Para tanto, o pó vacinal $(10 \mathrm{mg})$ foi reconstituído em $0,5 \mathrm{~mL}$ de solução fisiológica tamponada adicionada de $0,3 \%$ de Tween 80 .

\subsection{ANÁLISE ESTATÍSTICA}

Aos resultados obtidos foram aplicados testes estatísticos correspondentes a aplicação de distribuiçāo " $t$ " de probabilidade com amostras dependentes ( $t$ pareado), à distribuição " $t$ " de probabilidades para amostras independentes, à análise de variância e à regressão linear, adotando como nível de significância $\alpha=0,05$; conforme indicaçōes de BERQUÓ et alii, 1981. 


\section{4 - RESULTADOS}

\section{1 - DETERMINAÇÃO DO CONSUMO DE OXIGÊNIO PELO MÉTODO POLA- ROGRÁFICO EM DIFERENTES CONCENTRAÇŌES DA VACINA BCG LIOFILI-} ZADA.

Com a finalidade de verificar a sensibilidade do método polarográfico, diferentes concentrações da vacina foram testadas em relação ao consumo de oxigênio e dosagem de proteína.

Como mostra a TABELA 1, a velocidade de consumo de oxigênio em $\mathrm{m} \mu \mathrm{MO} 2 / \mathrm{s}$, variou conforme a concentraçāo das amostras $(\mathrm{mg})$ sendo proporcional à quantidade de proteína $(\mathrm{mg} / \mathrm{mL})$.

TABELA 1 - Valores do consumo de oxigênio $\left(\mathrm{m} \mu \mathrm{MO}_{2} / \mathrm{s}\right)$ determinado pelo método polarográfico em diferentes concentrações da vacina BCG liofilizada ${ }^{*} \mathrm{e}$ respectivas dosagens de proteína $(\mathrm{mg} / \mathrm{mL})$. Instituto Butantan, S.P., 1990.

\begin{tabular}{ccc}
\hline $\begin{array}{c}\text { Concentração da vacina } \\
\text { BCG liofilizada } \\
(\mathrm{mg})\end{array}$ & $\begin{array}{c}\text { Consumo de oxigênio } \\
(\mathrm{m} \mu \mathrm{MO} 2 / \mathrm{s})\end{array}$ & $\begin{array}{c}\text { Dosagem de proteína } \\
(\mathrm{mg} / \mathrm{mL})\end{array}$ \\
\hline 1 & 0,0194 & 0,12 \\
2 & 0,0240 & - \\
3 & 0,0333 & 0,21 \\
5 & 0,0616 & 0,36 \\
10 & 0,1054 & 0,56 \\
20 & 0,2177 & 0,87 \\
50 & 0,3762 & - \\
100 & 0,5075 & - \\
\hline
\end{tabular}

* Lote - I.B. $36 / 88$ 
Com os dados da TABELA 1 construiu-se a FIGURA 6 que mostra graficamente, o consumo de oxigênio da vacina BCG liofilizada (lote I.B. 36/88), medido por polarografia, em diferentes concentraçōes, por onde se verifica a aparente linearidade na medida de consumo de oxigênio em concentrações de 1 a 20 mg da vacina.

No estudo da regressão linear, a correlação existente entre concentração da vacina na faixa de 1 a $20 \mathrm{mg}$ e velocidade de consumo de oxigênio forneceu para os parâmetros da equação, os valores $a=0,0056 \mathrm{e} b=0,0105$, com um coeficiente de correlação $\mathrm{r}=0,9986$. O mesmo estudo feito entre concentração proteica e velocidade de consumo de oxigênio, forneceu para os parâmetros da equação os valores $a=$ $-0,0239$ e $b=0,2626$, com um coeficiente de correlação $r=0,9859$.



FIGURA 6 - Representação gráfica do consumo de oxigênio da vacina BCG liofilizada, em função da sua concentraçāo. 


\section{2 - DETERMINAÇÃO DO CONSUMO DE OXIGENIO, PELO MÉTODO POLA- ROGRÁFICO, DE TRES LOTES DA VACINA BCG LIOFILIZADA, SUBMETIDOS A DIFERENTES TEMPERATURAS.}

O consumo de oxigênio da vacina BCG liofilizada submetida às temperaturas de $42^{\circ} \mathrm{C}$ por 60 minutos, e $56^{\circ} \mathrm{C}, 70^{\circ} \mathrm{C}$ e $100^{\circ} \mathrm{C}$ por 15 minutos foi comparado com aquelas mantidas em temperatura adequada $\left(2 \mathrm{a} 8^{\circ} \mathrm{C}\right)$, após reconstituição em solução fisiológica tamponada com a finalidade de verificar a confiabilidade do método polarográfico.

A TABELA 2 mostra os resultados da velocidade de consumo de oxigênio em $\mathrm{m} \mu \mathrm{MO} 2 / \mathrm{s} / 10 \mathrm{mg}$ e a sobrevida do $\mathrm{BCG}$ em diferentes temperaturas em relaçāo às amostras mantidas em condiçōes adequadas de temperatura.

TABELA 2 - Determinação do consumo de oxigênio ( $\mathrm{m} \mu \mathrm{MO} 2 / \mathrm{s} / 10 \mathrm{mg}$ ), pelo método polarográfico de três lotes de vacina BCG liofilizada, submetidos a diferentes temperaturas (C) e tempos (minuto), assim como sua sobrevida (\%). Instituto Butan$\tan$ S.P., 1990.

\begin{tabular}{cccc}
\hline $\begin{array}{c}\text { Temperatura } \\
{ }^{\circ} \mathrm{C}\end{array}$ & $\begin{array}{c}\text { Tempo } \\
\text { (minutos) }\end{array}$ & $\begin{array}{c}\text { Consumo de } \\
\text { oxigênio } \\
(\mathrm{m} \mu \mathrm{MO} 2 / \mathrm{s} / 10 \mathrm{mg})\end{array}$ & $\begin{array}{c}\text { Sobrevida } \\
\%\end{array}$ \\
\hline 42 & 60 & $0,0582^{*}$ & 39,22 \\
42 & 60 & $0,0550^{* *}$ & 35,26 \\
42 & 60 & $0,0500^{* * *}$ & 35,01 \\
56 & 15 & $0,0000^{* * * *}$ & 0 \\
70 & 15 & $0,0000^{* * * *}$ & 0 \\
100 & 15 & $0,0000^{* * * *}$ & 0 \\
\hline controle & - & $0,1484^{*}$ & 100 \\
2 a $8{ }^{\circ} \mathrm{C}$ & - & $0,1560^{* *}$ & 100 \\
& - & $0,1428^{* * *}$ & 100 \\
\hline
\end{tabular}

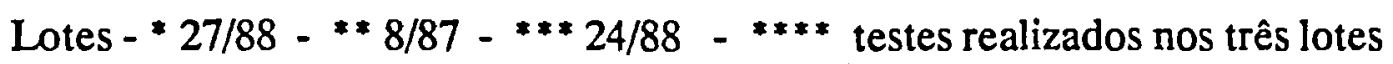




\section{3 - TESTE DE DIFERENTES DILUENTES PARA A RECONSTITUIÇĀO DA VACINA BCG LIOFILIZADA.}

Ao se comparar diferentes diluentes empregados para a reconstituiçāo da vacina BCG liofilizada (meio líquido de Sauton 1:4, solução de glutamato de sódio a $2 \%$, soluçāo fisiológica tamponada, soluçāo fisiológica tamponada adicionada de $0,1 \%, 0,2 \%$ ou $0,3 \%$ de Tween 80 ), verificou-se através de microscopia 6 ptica, que 0 diluente que proporcionou melhor homogeneidade da suspensão, sem formação de grumos, foi a solução fisiológica tamponada adicionada de $0,3 \%$ de.Tween 80 .

Quando o meio de Sauton foi utilizado como diluente, observou-se que, além de nāo evitar a formação de grumos da suspensão, ocorreu também, contaminação do meio, fato nāo observado quando da utilização de outros diluentes.

\section{4 - ESTUDO COMPARATIVO DA VIABILIDADE DA VACINA BCG LIOFILIZA- DA PELO MÉTOdo POLAROGRÁfICO , PELO MÉTODO DE WARBURG E PELA DETERMINAÇÃO DO NÚMERO DE UNIDADES FORMADORAS DE CO- LÓNIAS (CONTAGEM DE COLÓNIAS)}

O estudo comparativo da viabilidade da vacina BCG liofilizada foi realizado utilizando-se um "pool" de amostras da vacina (resultados TABELAS 3 a 7) e 34 amostras de diferentes lotes da vacina avaliados separadamente, pelo método polarográfico, pelo método de Warburg e o de contagem de colônias, estes dois últimos realizados pelo controle de qualidade do Laboratório de Vacina BCG Intradérmica do Instituto Butantan (TABELAS 8 a 12).

Para cada experimento foi utilizado um "pool" de 30 ampolas de vacina BCG liofilizada provenientes de diferentes lotes da vacina, reconstituídas em solução fisiológica tamponada de maneira a conter $10 \mathrm{mg}$ por $\mathrm{mL}$, cuja respiração foi simultaneamente medida por polarografia e por manometria, além de ter sido procedida a determinação do número de unidades formadoras de colônias.

Os resultados da viabilidade de "pool" de amostras da vacina BCG liofilizada, segundo os métodos polarográfico, Warburg e contagem de colônias estão apresentados na TABELA 3. 
TABELA3 - Estudo comparativo da viabilidade de "pool" de amostras de vacina BCG liofilizada segundo os métodos utilizados. Instituto Butantan, S.P., 1990.

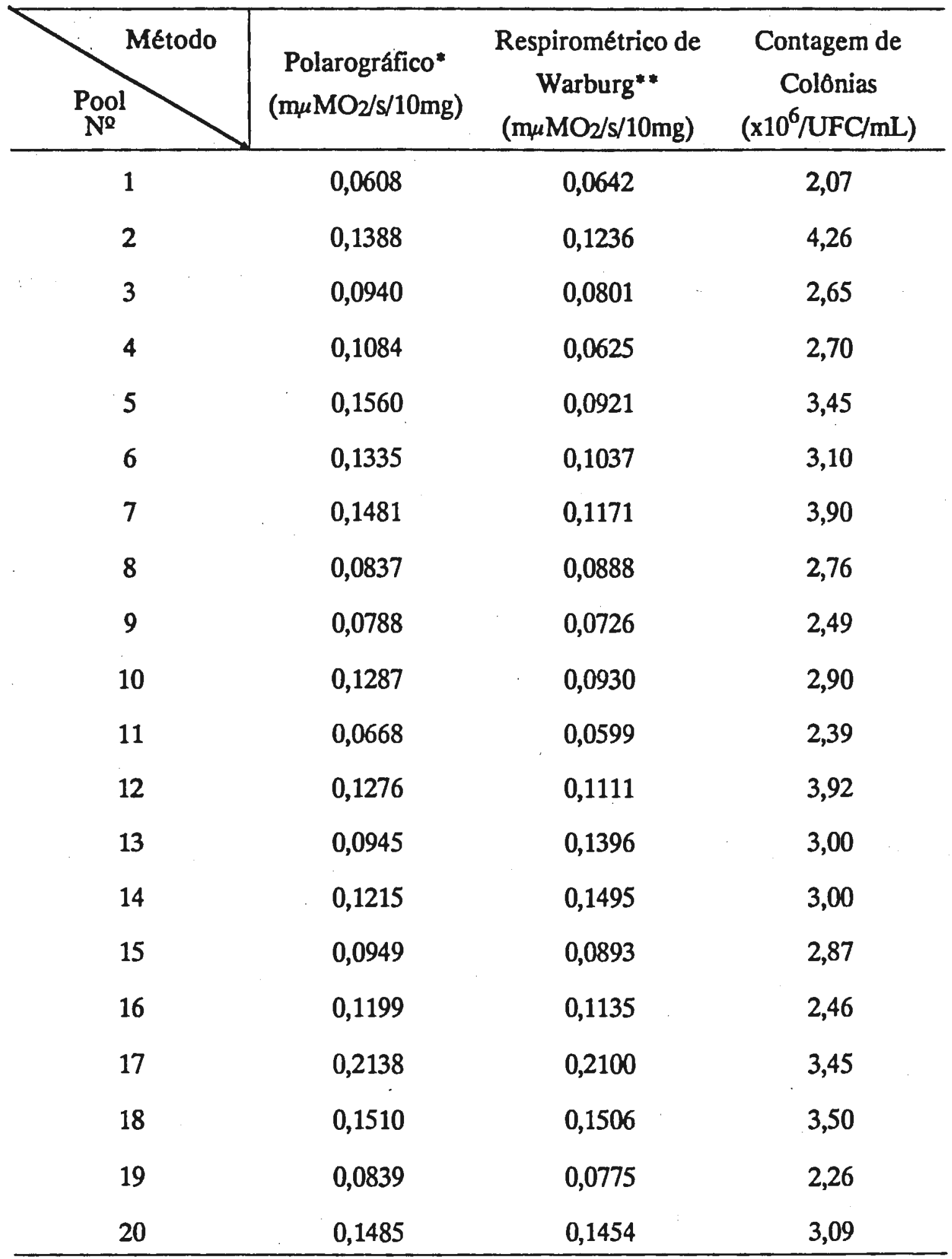

* Média de três determinaçōes.

** Média de duas determinações, onde a unidade da respirometria de Warburg foi convertida em $\mathrm{m} \mu \mathrm{MO} 2 / \mathrm{s}$ para $10 \mathrm{mg}$ de pó vacinal, conforme descrito anteriormente (Material e Métodos). 
Após a determinaçăo da viabilidade da vacina BCG liofilizada pelos trés métodos descritos, foram realizadas análises comparativas entre os diferentes métodos.

Com os dados da TABELA 3 processou-se os tratamentos estatísticos representados nas TABELAS 4, 5, 6 e 7 .

A TABELA 4 apresenta os resultados do consumo de oxigênio pelos métodos polarográfico e Warburg com os valores das médias aritméticas, os desvios padrão e a variância.

TABELA 4 - Avaliação da determinação de consumo de oxigênio ( $\mathrm{m} \mu \mathrm{MO} 2 / \mathrm{s} / 10 \mathrm{mg}$ ) da vacina BCG liofilizada ("pool"), segundo os métodos, parâmetros e aplicaçāo de "t" pareado. Instituto Butantan, S.P., 1990.

\begin{tabular}{cccc}
\hline Método & $\begin{array}{c}\text { Polarográfico } \\
(\mathrm{m} \mu \mathrm{MO} 2 / \mathrm{s} / 10 \mathrm{mg})\end{array}$ & $\begin{array}{c}\text { Warburg } \\
(\mathrm{m} \mu \mathrm{MO} / \mathrm{s} / 10 \mathrm{mg})\end{array}$ & $\begin{array}{c}\text { Estatística } \\
\text { "t" }\end{array}$ \\
\hline Parâmetros & $(\mathrm{x})$ & $(\mathrm{y})$ & \\
\hline Média & 0,118 & 0,107 & $1,95 \mathrm{NS}^{*}$ \\
Desvio Padrão & 0,037 & 0,038 & \\
Variância & 0,001 & 0,001 & \\
\hline
\end{tabular}

* NS = não significante

$\mathrm{T} a^{0,05}=2,093$

GL19

Através de análise estatística com o teste " $t$ " pareado, não se observou diferença entre os métodos polarográfico e Warburg, a nível de $a=0,05$.

A TABELA 5 apresenta os resultados comparativos da determinação do consumo de oxigênio pelo método polarográfico e a determinação do número de unidades formadoras de colônias pelo método de contagem de colónias. 
TABELA 5 - Resultados da regressão linear da determinação de consumo de oxigênio (muMO2/s/10mg) e número de UFC $\left(\times 10^{6} \mathrm{UFC} / \mathrm{mL}\right)$ da vacina $B C G$ liofilizada ("pool"), segundo os métodos utilizados. Instituto Butantan, S.P., 1990.

\begin{tabular}{ccc}
\hline Método & $\begin{array}{c}\text { Polarográfico } \\
(\mathrm{m} \mu \mathrm{MO} / \mathrm{s} / 10 \mathrm{mg})\end{array}$ & $\begin{array}{c}\text { Contagem de Colónias } \\
\left(\mathrm{x} 10^{6} \mathrm{UFC} / \mathrm{mL}\right)\end{array}$ \\
\hline Parâmetros & $(\mathrm{x})$ & $(\mathrm{y})$ \\
\hline Média & 0,118 & 3,011 \\
Variância & 0,0014 & 0,345 \\
Desvio Padrão & 0,0370 & 0,587 \\
\hline Interseçāo & $\mathrm{A}=1,6819$ & \\
Coef. Angular & $\mathrm{B}=11,296$ & \\
Correlação & $\mathrm{r}=0,7113$ & \\
Coef. Determ. & $\mathrm{r}^{2}=0,5060$ \\
\hline
\end{tabular}

$$
\begin{gathered}
\mathrm{TC}=4,29>\mathrm{ta} \\
\mathrm{GL} 18
\end{gathered}
$$

O resultado da regressão linear apresentou uma correlação positiva de alta intensidade e significante entre os dois métodos analisados.

A TABELA 6 apresenta os resultados comparativos da determinação do consumo de oxigênio pelo método de Warburg e a determinação do número de unidades formadoras de colónias, pelo método de contagem de colônias.

TABELA 6 - Resultados da regressāo linear de determinaçāo de consumo de oxigênio ( $\left.m \mu \mathrm{MO}_{2} / \mathrm{s} / 10 \mathrm{mg}\right)$ e número de UFC $\left(\times 10^{6} \mathrm{UFC} / \mathrm{mL}\right)$, da vacina BCG liofilizada ("pool"), segundo os métodos utilizados. Instituto Butantan, S.P., 1990.

\begin{tabular}{ccc}
\hline Método & $\begin{array}{c}\text { Warburg } \\
\left(\mathrm{m} \mu \mathrm{MO}_{2} / \mathrm{s} / 10 \mathrm{mg}\right)\end{array}$ & $\begin{array}{c}\text { Contagem de Colônias } \\
\left(\mathrm{x} 10^{6} \mathrm{UFC} / \mathrm{mL}\right)\end{array}$ \\
\hline Parâmetros & $(\mathrm{x})$ & $(\mathrm{y})$ \\
\hline Média & 0,1070 & 3,011 \\
Variância & 0,0014 & 0,345 \\
Desvio Padrão & 0,0378 & 0,0587 \\
\hline Interseçāo & $\mathrm{A}=2,0895$ \\
Coef. Angular & $\mathrm{B}=8,5953$ \\
Correlaçāo & $\mathrm{r}=0,5537$ \\
Coef. Determ. & $\mathrm{r}^{2}=0,3066$ \\
\hline \multicolumn{2}{c}{$\mathrm{TC}=2,82>\mathrm{ta}{ }^{0,05}=2,101$} \\
\end{tabular}


O resultado da regressão linear mostrou uma correlação de média intensidade e significante entre os dois métodos analisados.

A TABELA 7 apresenta os resultados comparativos de consumo de oxigênio entre os métodos polarográfico e Warburg.

TABELA 7 - Resultado da regressão linear da determinação do consumo de oxigênio ( $m \mu \mathrm{MO} 2 / \mathrm{s} / 10 \mathrm{mg}$ ) da vacina BCG liofilizada ("pool"), segundo os métodos utilizados. Instituto Butantan, S.P., 1990.

\begin{tabular}{ccc}
\hline Método & $\begin{array}{c}\text { Polarográfico } \\
(\mathrm{m} \mu \mathrm{MO} 2 / \mathrm{s} / 10 \mathrm{mg})\end{array}$ & $\begin{array}{c}\text { Warburg } \\
(\mathrm{m} \mu \mathrm{MO} 2 / \mathrm{s} / 10 \mathrm{mg})\end{array}$ \\
\hline Parâmetros & $(\mathrm{x})$ & $(\mathrm{y})$ \\
\hline Média & 0,1177 & 0,107 \\
Variância & 0,0014 & 0,001 \\
Desvio Padrão & 0,0370 & 0,038 \\
\hline Interseção & $\mathrm{A}=0,0115$ & \\
Coef. Angular & $\mathrm{B}=0,8133$ & \\
Correlação & $\mathrm{r}=0,7950$ & $\mathrm{~T}$ \\
Coef. Determ. & $\mathrm{r}^{2}=0,6320$ & $\mathrm{TC}=5,56>\mathrm{ta}^{0,05}=2,101$ \\
\end{tabular}

O resultado da regressāo linear mostrou uma correlação de alta intensidade e significante entre os dois métodos analisados.

A TABELA 8 apresenta os resultados obtidos da determinação da viabilidade em diferentes lotes da vacina BCG liofilizada avaliadas pelo método polarográfico com aqueles obtidos pelo controle de qualidade do Laboratório de Vacina BCG Intradérmica do Instituto Butantan realizados pelo método de Warburg para determinação do consumo de oxigênio e pelo método de contagem de colónias para a determinação do número de unidades formadoras de colônias. 
TABELA 8 - Estudo comparativo da viabilidade da vacina BCG liofilizada em diferentes lotes segundo os métodos utilizados. Instituto Butantan, S.P., 1990.

\begin{tabular}{|c|c|c|c|c|}
\hline Lote I & Método & $\begin{array}{c}\text { Polarográfico* } \\
\left(\mathrm{m} \mu \mathrm{MO}_{2} / \mathrm{s} / 10 \mathrm{mg}\right)\end{array}$ & $\begin{array}{c}\text { Warburg** } \\
\left(\mathrm{m} \mu \mathrm{MO}_{2} / \mathrm{s} / 10 \mathrm{mg}\right)\end{array}$ & $\begin{array}{c}\text { Contagem de colônias** } \\
\left(\times 10^{6} \mathrm{UFC} / \mathrm{mL}\right)\end{array}$ \\
\hline 1 & $2 / 87$ & 0,0719 & 0,0643 & 2,94 \\
\hline 2 & $8 / 87$ & 0,1320 & 0,1236 & 4,26 \\
\hline 3 & $1 / 88$ & 0,0912 & 0,0802 & 2,99 \\
\hline 4 & $24 / 88$ & 0,1326 & 0,1038 & 2,31 \\
\hline 5 & $27 / 88$ & 0,1483 & 0,1172 & 3,45 \\
\hline 6 & $32 / 88$ & 0,0952 & 0,0889 & 2,94 \\
\hline 7 & $33 / 88$ & 0,0847 & 0,0726 & 2,77 \\
\hline 8 & $36 / 88$ & 0,1218 & 0,0931 & 2,90 \\
\hline 9 & $37 / 88$ & 0,0668 & 0,0600 & 2,37 \\
\hline 10 & $2 / 89$ & 0,1490 & 0,1073 & 2,93 \\
\hline 11 & $3 / 89$ & 0,1225 & 0,1319 & 2,95 \\
\hline 12 & $4 / 89$ & 0,1056 & 0,1103 & 3,84 \\
\hline 13 & $5 / 89$ & 0,1537 & 0,1112 & 4,19 \\
\hline 14 & $6 / 89$ & 0,1122 & 0,1397 & 3,65 \\
\hline 15 & $8 / 89$ & 0,0949 & 0,0893 & 3,35 \\
\hline 16 & 9/89 & 0,0929 & 0,1379 & 3,62 \\
\hline 17 & $11 / 89$ & 0,1070 & 0,1135 & 3,06 \\
\hline 18 & $12 / 89$ & 0,2138 & 0,2100 & 4,27 \\
\hline 19 & $13 / 89$ & 0,1472 & 0,1506 & 3,97 \\
\hline 20 & $14 / 89$ & 0,0966 & 0,1037 & 2,38 \\
\hline 21 & $15 / 89$ & 0,0762 & 0,0775 & 2,30 \\
\hline 22 & $16 / 89$ & 0,1461 & 0,1454 & 2,90 \\
\hline 23 & $17 / 89$ & 0,0907 & 0,0766 & 2,50 \\
\hline 24 & $18 / 89$ & 0,0687 & 0,0682 & 2,54 \\
\hline 25 & $19 / 89$ & 0,0865 & 0,0958 & 2,80 \\
\hline 26 & $21 / 89$ & 0,0679 & 0,0652 & 2,04 \\
\hline 27 & $22 / 89$ & 0,0802 & 0,0664 & 2,04 \\
\hline 28 & $23 / 89$ & 0,0676 & 0,0629 & 2,08 \\
\hline 29 & $24 / 89$ & 0,0927 & 0,0710 & 3,09 \\
\hline 30 & $25 / 89$ & 0,0967 & 0,0866 & 2,19 \\
\hline 31 & $29 / 89$ & 0,0991 & 0,0789 & 3,36 \\
\hline 32 & $31 / 89$ & 0,1146 & 0,1082 & 4,15 \\
\hline 33 & $32 / 89$ & 0,1452 & 0,1539 & 3,82 \\
\hline 34 & $87 / 07 / 24$ & 0,0887 & 0,0829 & 3,00 \\
\hline
\end{tabular}

"Média de três determinações. "Média de duas determinações. 
Com os dados da TABELA 8, processou-se os tratamentos estatísticos representados nas TABELAS 9, 10, 11 e 12.

A TABELA 9 apresenta os resultados do consumo de oxigênio pelos métodos polarográfico e de Warburg, com os valores das médias aritméticas, os desvios padrão e variância nos 34 lotes de vacina BCG liofilizada.

TABELA 9 - Avaliação da determinação do consumo de oxigênio ( $\mathrm{m} \mu \mathrm{MO} / \mathrm{s} / 10 \mathrm{mg}$ ) dos 34 lotes de vacina BCG liofilizada, segundo os métodos utilizados e aplicaçāo de " $t$ " para médias independentes. Instituto Butantan, S.P., 1990

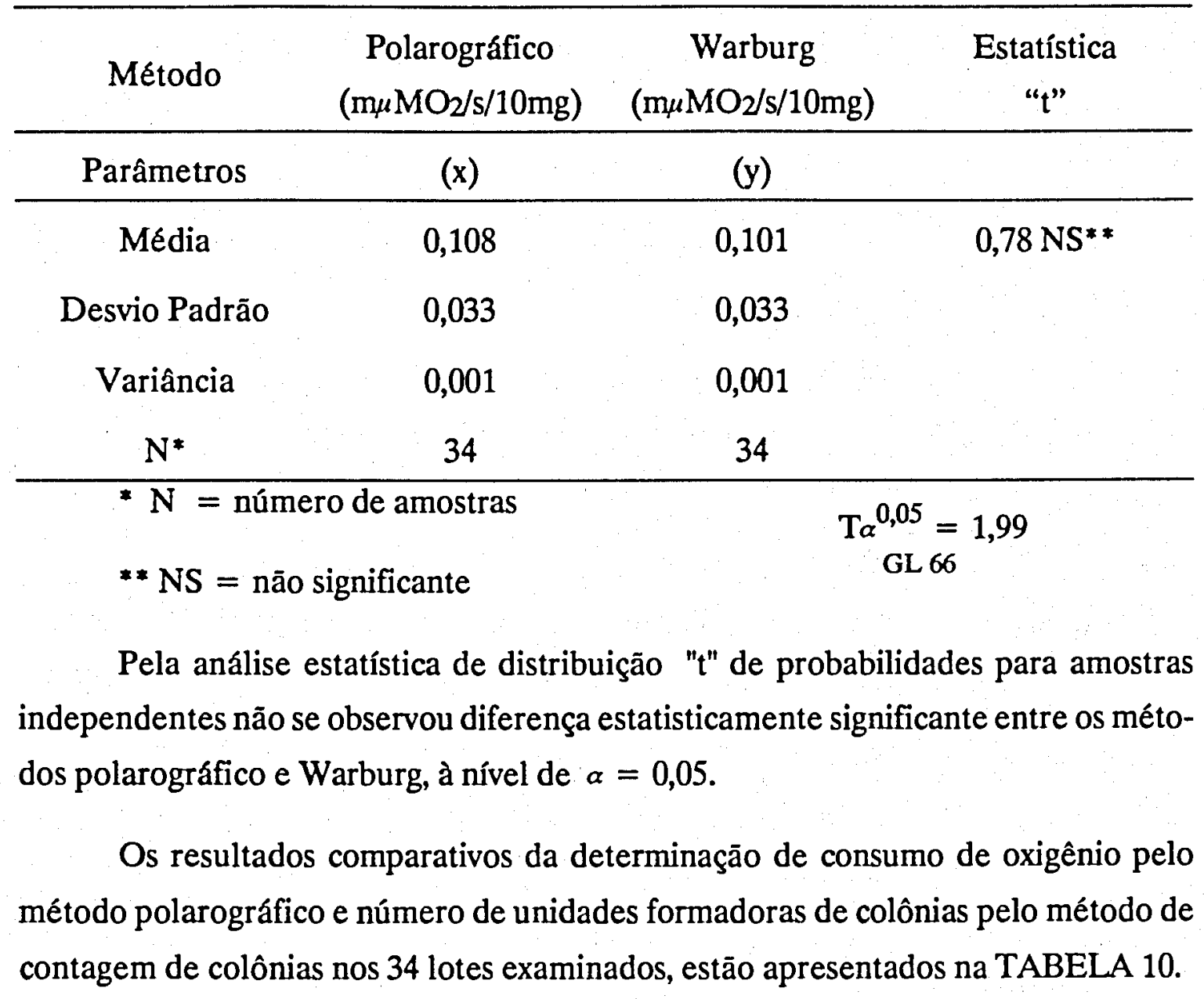


TABELA 10 - Resultados da regressão linear da determinação de consumo de oxigênio (mభ $\mathrm{MO}_{2} / \mathrm{s} / 10 \mathrm{mg}$ ) e número de UFC ( $\left.\times 10^{6} \mathrm{UFC} / \mathrm{mL}\right)$ dos 34 lotes de vacina BCG liofilizada, segundo os métodos utilizados. Instituto Butantan, S.P., 1990.

\begin{tabular}{ccc}
\hline Método & $\begin{array}{c}\text { Polarográfico } \\
(\mathrm{m} \mu \mathrm{MO} / \mathrm{s} / 10 \mathrm{mg})\end{array}$ & $\begin{array}{c}\text { Contagem de Colônias } \\
\left(\times 10^{6} \mathrm{UFC} / \mathrm{mL}\right)\end{array}$ \\
\hline Parâmetros & $(\mathrm{x})$ & $(\mathrm{y})$ \\
\hline Média & 0,1077 & 3,057 \\
Variância & 0,0011 & 0,458 \\
Desvio Padrão & 0,0327 & 0,676 \\
\hline Interseção & $\mathrm{A}=1,6026$ & \\
Coef. Angular & $\mathrm{B}=13,5115$ & \\
Correlação & $\mathrm{r}=0,6530$ & \\
Coef. Determ. & $\mathrm{r}=0,4264$ & \\
\hline
\end{tabular}

$$
\mathrm{TC}=4,87>\mathrm{ta}_{\mathrm{GL} 32}^{0,05}=2,036
$$

Os resultados da regressão linear apresentaram uma correlação positiva de alta intensidade e significante entre os dois métodos analisados.

Os resultados comparativos da determinação do consumo de oxigênio pelo método de Warburg e número de unidades formadoras de colônias pelo método de contagem de colônias nos 34 lotes examinados estão apresentados na TABELA 11.

TABELA 11 - Resultado da regressão linear da determinação de consumo de oxigênio (m $\mu \mathrm{MO} 2 / \mathrm{s} / 10 \mathrm{mg}$ ) e número de $\mathrm{UFC}\left(\times 10^{6} \mathrm{UFC} / \mathrm{mL}\right)$ dos 34 lotes da vacina

\begin{tabular}{|c|c|c|}
\hline Método & $\begin{array}{c}\text { Warburg } \\
\text { (m } \mu \mathrm{MO} 2 / \mathrm{s} / 10 \mathrm{mg})\end{array}$ & $\begin{array}{c}\text { Contagem de Colônias } \\
\left(\times 10^{6} \text { UFC/mL) }\right.\end{array}$ \\
\hline Parámetros & $(x)$ & $(\mathrm{y})$ \\
\hline Média & 0,1014 & 3,057 \\
\hline Variância & 0,0011 & 0,458 \\
\hline Desvio Padrāo & 0,0334 & 0,676 \\
\hline Interseçāo & $A=1,6473$ & \\
\hline Coef. Angular & $B=13,9015$ & \\
\hline Correlação & $r=0,6868$ & \\
\hline Coef. Determ. & $r^{2}=0,4717$ & \\
\hline \multicolumn{3}{|c|}{  } \\
\hline
\end{tabular}
BCG liofilizada, segundo os métodos utilizados. Instituto Butantan, S.P., 1990. 
Os resultados da regressão linear mostraram uma correlaçāo positiva de alta intensidade e significante entre os dois métodos analisados.

A TABELA 12 apresenta os resultados comparativos de consumo de oxigênio entre os métodos polarográfico e Warburg nos 34 lotes examinados.

TABELA 12 - Resultados da regressão linear da determinaçăo do consumo de oxigênio ( $\mathrm{m} \mu \mathrm{MO} / \mathrm{s} / 10 \mathrm{mg}$ ) dos 34 lotes da vacina BCG liofilizada, segundo os métodos utilizados. Instituto Butantan, S.P., 1990.

\begin{tabular}{ccc}
\hline Método & $\begin{array}{c}\text { Polarográfico } \\
(\mathrm{m} \mu \mathrm{MO} 2 / \mathrm{s} / 10 \mathrm{mg})\end{array}$ & $\begin{array}{c}\text { Warburg } \\
(\mathrm{m} \mu \mathrm{MO} / \mathrm{s} / 10 \mathrm{mg})\end{array}$ \\
\hline Parâmetros & $(\mathrm{x})$ & $(\mathrm{y})$ \\
\hline Média & 0,1077 & 0,101 \\
Variância & 0,0011 & 0,001 \\
Desvio Padrão & 0,0327 & 0,033 \\
\hline Interseção & $\mathrm{A}=0,0066$ & \\
Coef. Angular & $\mathrm{B}=0,8808$ & \\
Correlação & $\mathrm{r}=0,8615$ & \\
Coef. Determ. & $\mathrm{r}^{2}=0,7422$ & \\
\hline
\end{tabular}

$$
\mathrm{TC}=9,59>\mathrm{ta}_{\text {GL } 32}^{0,05}=2,036
$$

Os resultados da regressão linear mostraram uma correlaçāo positiva de alta intensidade e significante entre os dois métodos analisados.

\subsection{AVALIAÇĀO DA REPRODUTIBILIDADE DO MÉTODO POLAROGRÁFICO EM DIFERENTES LOTES DE VACINA BCG LIOFILIZADA.}

A adiçāo de $0,3 \%$ de Tween 80 à solução fisiológica tamponada para a reconstituição da vacina BCG liofilizada, na avaliaçāo do consumo de oxigênio pelo método polarográfico, em 98 determinaçōes, reproduziu os dados com coeficientes de variabilidade entre 5,9 a $18,7 \%$, nos 12 lotes estudados (TABELA 13). 
TABELA 13 - Avaliação do consumo de oxigênio (muMO2/s/10mg) em polarógrafo, utililizando $0,5 \mathrm{~mL}$ de soluçāo fisiológica tamponada adicionada de $0,3 \%$ de Tween 80 , na reconstituição do pó vacinal $(10 \mathrm{mg})$, em 12 lotes da vacina BCG liofilizada, em 98 testes realizados. Instituto Butantan, S.P., 1990.

\begin{tabular}{ccccc}
\hline Lote número & $\begin{array}{c}\text { Consumo de } \\
\text { No de testes } \\
\text { por Lote }\end{array}$ & $\begin{array}{c}\text { oxigênio } \\
(\mathrm{m} \mu \mathrm{MO} / \mathrm{s} / \mathrm{mg}) \\
(\mathrm{média})\end{array}$ & Desvio Padrāo & $\begin{array}{c}\text { Coeficiente de } \\
\text { Variabilidade } \\
(\%)\end{array}$ \\
\hline $1-09 / 89$ & 4 & 0,0904 & 0,0055 & 6,1 \\
$2-11 / 89$ & 10 & 0,0995 & 0,0099 & 9,9 \\
$3-12 / 89$ & 4 & 0,2034 & 0,0234 & 11,5 \\
$4-13 / 89$ & 7 & 0,1425 & 0,0106 & 7,0 \\
$5-15 / 89$ & 7 & 0,0789 & 0,0047 & 5,9 \\
$6-17 / 89$ & 7 & 0,0944 & 0,0083 & 8,8 \\
$7-24 / 89$ & 4 & 0,0898 & 0,0090 & 10,0 \\
$8-25 / 89$ & 7 & 0,1034 & 0,0163 & 15,7 \\
$9-29 / 89$ & 6 & 0,1089 & 0,0173 & 15,8 \\
$10-31 / 89$ & 11 & 0,1152 & 0,0173 & 15,0 \\
$11-32 / 89$ & 14 & 0,1136 & 0,0212 & 18,7 \\
$12-87 / 07 / 24$ & 17 & 0,1047 & 0,0151 & 14,4 \\
\hline
\end{tabular}

A análise de variância e o teste " $t$ " de Student, mostraram não haver diferença estatisticamente significante nas várias determinações em um mesmo lote, a nivel de $a=0,05$ nos 12 lotes avaliados da TABELA 13. 


\section{5 - DISCUSSÃO}

Um dos testes exigidos para um rigido controle de qualidade da vacina BCG liofilizada é a determinação de sua viabilidade (KANTOR et alii, 1983).

Segundo BORREMANS et alii (1983) e van HEMERT \& TIESJEMA (1977), o único teste para viabilidade da vacina BCG exigido pela OMS é o da determinação do número de unidades formadoras de colônias. MILSTEIN \& GIBSON (1990) consideram este teste o mais confíavel sem, entretanto, desprezar os demais métodos. Porém, de acordo com os autores citados, o teste em que se faz a contagem do número de partículas está sujeito a consideráveis variabilidades, dependendo do tipo de meio utilizado, dos componentes do meio e dos procedimentos do teste.

As limitações do método de cultivo para testar a viabilidade da vacina BCG são bem conhecidas. Todavia, quando métodos padronizados são usados, os resultados são confiáveis. Cuidados devem ser tomados nos fatores que poderiam influenciar os resultados da contagem de colônias, tais como, origem dos ingredientes, especialmente ovos para o preparo do meio de Lowenstein - Jensen; preparação e coagulação do meio; escolha da diluição apropriada; uso de duas diluições em série, ou seja, duplicata das diluiçōes; qualificação do pessoal; método de análise estatística dos resultados, etc.

Dentre os métodos para a determinação da viabilidade da vacina BCG liofilizada está o do consumo de oxigênio utilizado pelo Laboratório de Vacina BCG Intradérmica do Instituto Butantan e por vários laboratórios internacionais, sendo que o mais comumente utilizado é o tradicional método respirométrico de Warburg.

Levando em consideração a importância do assunto, bem como a indubitável necessidade de proporcionar aos laboratórios que se dedicam à sua produção, de um método mais adequado para o controle de qualidade da vacina BCG liofilizada e, mais ainda, tendo em conta a necessidade de prover as Unidades de Saúde responsáveis pela imunização da população, de um método satisfatório, de rápida execução e de fácil manejo, capaz de proporcionar dados seguros sobre a viabilidade das vacinas a serem utilizadas, foi objetivo do presente trabalho buscar um método de escolha que preenchesse tais finalidades. 
$E$ bem verdade que um dos testes de controle de qualidade da vacina BCG liofilizada levado a efeito pela técnica respirométrica de Warburg, $€$ plenamente aceito por todos os organismos internacionais que controlam esse tipo de atividade, dentre eles a OMS.

Nesse particular van HEMERT \& TIESJEMA (1977) haviam já feito alguns estudos comparativos entre os valores de consumo de oxigênio, medidos pela técnica de Warburg e pelo oxígrafo de Gilson, com a contagem de colonias, tendo melhor correlação entre valores de consumo de oxigênio e a reatividade da pele de cobaios à tuberculina, do que contagem de colônias e o mesmo teste tuberculínico. Por outro lado, van HEMERT \& TIESJEMA (1977) ainda indagam, qual seria o melhor parâmetro capaz de refletir a potência da vacina humana.

Em trabalho posterior, van den HEUVEL et alii (1981) buscaram otimizar as medidas de consumo de oxigênio da vacina BCG com o oxígrafo de Gilson, trabalhando com 10 amostras da vacina, tendo assinalado, porém, diferenças de até $50 \% \mathrm{em}$ uma série de experimentos paralelos. Na otimizaçāo do processo, esses autores empregaram Tween 80 para evitar a formação de grumos, tendo reduzido a $10 \%$ as diferenças entre amostras paralelas.

Apesar dos trabalhos de van HEMERT \& TIESJEMA (1977) e de van den HEUVEL et alii (1981) nenhum progresso foi feito até o presente momento e nenhum estudo mais acurado desse problema foi levado a efeito, com os métodos tradicionais ainda em pleno uso em todos os laboratórios do mundo que se dedicam a esse assunto.

ENGIBAROV et alli (1986), por sua vez, estudando o problema dos exames de laboratório e o controle de pós-vacinação em trabalhos de campo assinalam claramente a necessidade de instrumentos para a rápida determinaçāo da viabilidade da vacina $B C G$. Em seus trabalhos, contudo. de controle de qualidade rotineiro da vacina BCG produzidos em Sofia, na Bulgária, entre outros procedimentos ainda utilizavam o método de Warburg, empregando $20 \mathrm{mg} / \mathrm{ml}$ de suspensão bacteriana.

Com respeito à medida do conteúdo em ATP da suspensão bacteriana do BCG, $\varepsilon$ conveniente comentar sobre o trabalho de BORREMANS et alii (1983) que estudaram o efeito da homogeneidade das suspensōes de BCG com relação à medida de consumo de oxigênio pelo método do oxígrafo e o conteúdo de ATP. Segundo estes autores o oxígrafo de Gilson ofereceu maiores vantagens, pois a medida pode ser 
efetuada em uma única amostra e não foi influenciada pelo grau de dispersão da bactéria quando constantemente agitada.

Assim, no presente trabalho, procedeu-se a um estudo comparativo, cuidadosamente conduzido, no sentido de analisar a conveniência dos métodos de medida da taxa de consumo de oxigênio pela clássica técnica respirométrica de Warburg e pela medida polarográfica utilizando eletrodo de oxigênio, em relação à determinação de unidades formadoras de colônias. Por outro lado, foi procedido estudo comparativo, suportado por análises estatísticas, para resultados obtidos com o método polarográfico e o de Warburg e também, de cada um deles, com contagem de colônias.

Para tanto foi desenvolvido um equipamento de polarografia, especialmente projetado para essa finalidade, com base em instrumentos anteriormente descritos por LUCCHIARI et alii (1984). Tal polarógrafo possui importantes características, particularmente por possuir o eletrodo de platina e mais o de referência $\mathrm{Ag}-\mathrm{AgCl}$ embutidos em uma peça única que ainda contém um sensor que permite controlar, com precisão, as variaçōes de temperatura que ocorrem na câmara de reação.

Por outro lado, o circuito eletrônico do polarógrafo é de fácil construção e constituído por material correntemente encontrado no comércio especializado.

Quanto ao método de Warburg, as determinaçōes foram feitas em equipamento BRAUN - MELSUNGEN, modelo 166, dotado de eficiente sistema de controle de temperatura.

Inicialmente, para testarmos a sensibilidade do método polarográfico, diversas concentraçōes da vacina BCG liofilizada foram testadas em relaçāo ao consumo de oxigênio, tendo sido verificada a existência de linearidade no consumo de oxigênio, desde $1 \mathrm{mg}$ até $20 \mathrm{mg}$ de vacina, fato que permite ampla margem de análise, particularmente em processo de rápida execuçāo. Por outro lado (TABELA 1), verifica-se, também, direta correlação entre a concentraçāo de proteína das amostras e a velocidade de consumo de oxigênio. $O$ estudo da correlação entre os valores da TABELA 1, pela regressāo linear, mostrou excelente correlaçāo linear tanto entre concentração de vacina liofilizada e consumo de oxigênio como entre concentração proteica e consumo de oxigênio, com coeficientes de correlaçāo 0,9986 e 0,9859, respectivamente. Face a este resultado, optou-se estudar o consumo de oxigênio da vacina $B C G$ liofilizada em função de seu peso seco antes que em função de seu conteúdo proteico. 
Da mesma maneira, os resultados referentes à medida de consumo de oxigênio em vacinas liofilizadas, submetidas a diferentes temperaturas (TABELA 2), quando comparadas com aquelas mantidas em temperatura adequada $\left(2\right.$ a $\left.8^{\circ} \mathrm{C}\right)$, mostraram a confiabilidade do método polarográfico. Após a reconstituição da vacina em solução fisiologica tamponada, verificou-se que aquelas mantidas durante 60 minutos a $42^{\circ} \mathrm{C}$ mostraram uma redução de cerca de $65 \%$ do consumo de oxigênio em comparação àquelas mantidas entre $2 \mathrm{a} 8^{\circ} \mathrm{C}$. Por sua vez, vacinas mantidas a $56^{\circ} \mathrm{C}$ ou mais, durante 15 minutos, não revelaram consumo de oxigênio pelas bactérias, significando que 0 BCG é muito sensível à exposição ao calor, levando à morte das bactérias.

Assim, o BCG mostra-se muito sensivel à ação do calor, conforme demonstrado pela TABELA 2, razão pela qual a determinação da viabilidade de vacinas a serem administradas à população deve ser, sem dúvida, uma constante preocupação das Unidades de Saúde responsáveis por essa atividade.

Dentre os diversos fatores que podem afetar a viabilidade da vacina BCG, a temperatura excede em importância.

De acordo com ten DAM (1984), 5 minutos de exposição à luz de sol, no Egito, reduz a viabilidade da vacina em $99 \%$, enquanto que na Dinamarca, essa redução é de 50\% (OPS, 1979). Observaçōes em nosso laboratório, durante estudos de determinação polarográfica de consumo de oxigênio em vacina BCG liofilizada revelaram, em amostras mantidas por 15 minutos à temperatura ambiente (verão) e com incidência de luz solar, redução apreciável no consumo de oxigênio (MALUCELLI, M.I.C., resultados nāo publicados).

Justifica-se, pois, a necessidade de prover as Unidades de Saúde de meios laboratoriais capazes de dar rápida e segura soluçāo ao importante problema de analisar a viabilidade de vacinas a serem utilizadas na imunização da população e, portanto, o método polarográfico aqui proposto revela-se muito adequado.

No que diz respeito à medida da viabilidade da vacina $B C G$ liofilizada, já em 1971, BUNCH - CHRISTENSEN havia assinalado que a determinação do consumo de oxigênio, entāo feita em respirômetro de Warburg, é teste quantitativo inteiramente dependente de organismos vivos, uma vez que bacilos mortos nāo consomem oxigênio.

A utilização de diferentes diluentes para a reconstituiçăo da vacina BCG liofilizada empregados no presente trabalho mostrou que a adição de $0,3 \%$ de Tween 
80 foi a que apresentou melhores resultados quando comparados com outros diluentes por evitar a formação de grumos. Este fato deve ser levado em consideração, uma vez que vacinas diluídas em soluçāo fisiológica tamponada, adicionada de $0,3 \%$ de Tween 80 e submetidas à determinação do consumo de oxigênio pelo método polarográfico, mostraram uma boa reprodutibilidade, uma vez que os coeficientes de variabilidade foram de 5,9 a 18,7\% (TABELA 13), sendo que o teste " $t$ " pareado $e$ a análise de variância não foram significantes $\alpha=0,05$. Durante as medidas de consumo de oxigênio realizadas com outros diluentes observaram-se uma grande variabilidade nos resultados. Acredita-se que o fato de não haver formaçāo de grumos pela adição de Tween 80 , contribui para a obtenção de uma suspensão mais homogênea, permitindo que a populaçāo bacteriana como um todo tenha acesso ao oxigênio, evitando desta maneira variações nos resultados experimentais. Esses resultados estāo de acordo com os de van den HEUVEL et alii (1981) que mostram que a utilização de baixas concentraçōes de detergentes (0,3\% de Tween $80 \mathrm{em}$ meio de Sauton diluído 1:4), a fim de evitar a formação de grumos, é essencial para a obtenção de valores que podem ser reproduzidos, de consumo de oxigênio, em oxígrafo de Gilson.

Por outro lado BONICKS et alii (1970) verificaram que a redução de nitratos a nitritos pelo M.tuberculosis aumenta na presença do Tween, provavelmente por sua propriedade de doador de elétrons. No caso presente, contudo, o efeito do Tween 80 sobre a respiração do $\mathrm{BCG}$ liofilizado se deve muito provavelmente à sua propriedade detergente que faz com que haja desagregação dos grumos do BCG, aumentando a superfície de respiração, aliás, em concordância com as observaçōes de van den HEUVEL at alii (1981) já citadas. Antes disso, UNGAR (1962) já havia utilizado outro detergente (triton WR 139) adicionado ao meio de Sauton para o cultivo do BCG.

E importante tecer consideraçōes sobre os estudos comparativos levados a efeito no presente trabalho, entre as determinaçōes de consumo de oxigênio medidas por polarografia e aquelas obtidas por manometria pelo respirômetro de Warburg e, ainda, em comparaçāo de ambos com a técnica usual e oficial da OMS da determinação de unidades formadoras de colônias.

Os estudos comparativos entre os métodos polarográfico, de Warburg e de contagem de colônias foram levados a efeito (TABELA 3) com 20 diferentes "pools" de lotes da vacina BCG liofilizada. Como pode ser observado pelos resultados constantes da TABELA 4, utilizando-se de análise estatística com o teste " $t$ " pareado 
não foram observadas diferenças significantes ao nível de $a=0,05$ entre os métodos polarográfico e Warburg, o que demonstra que os métodos são equivalentes entre si.

Os dados obtidos nas TABELAS 5, 6 e 7, mostraram boa correlação entre os três métodos utilizados.

A regressão linear obtida entre os dados polarográficos e os manométricos revelou correlaçāo positiva de alta intensidade $(r=0,7950)$ e significante ao nivel de $\alpha=0,05$, demonstrando que o método polarográfico, poderá substituir, com vantagem, o manométrico, nos procedimentos de controle de qualidade da vacina BCG liofilizada.

Por sua vez, a regressāo linear obtida entre os dados polarográfico e os de contagem de colônias revelou correlaçāo positiva de alta intensidade $(r=0,7113)$ e significante ao nível de $\alpha=0,05$, enquanto que a regressão linear obtida entre os dados manométricos e os de contagem de colônias revelou correlaçāo positiva de média intensidade $(r=0,5537)$ e significante ao nível de $\alpha=0,05$.

É muito importante assinalar que os estudos comparativos entre os métodos polarográfico, de Warburg e o de contagem de colônias foram levados a efeito (TABELA 8) com 34 lotes de vacinas, cada lote sendo submetido, simultaneamente, aos três métodos indicados.

A regressão linear (dos dados da TABELA 8) entre o método polarográfico e o de contagem de colónias revelou correlação positiva de alta intensidade $(r=0,6530)$ e significante ao nível de $a=0,05$.

No caso dos métodos de Warburg e de contagem de colônia, os valores foram de $r=0,6868$ e significante ao nível de $a=0,05$.

Por outro lado, no caso dos métodos polarográfico e de Warburg, a correlação positiva foi de alta intensidade $r=0,8615$ e, certamente, significante ao nível de $a=0,05$.

Quanto à análise estatística (TABELA 9), os resultados apresentados entre o método polarográfico e o de Warburg foram não significantes, demonstrando que ambos os testes dāo resultados confiavelmente semelhantes.

Ao verificar-se as vantagens e desvantagens dos métodos analisados, acrescenta-se as seguintes vantagens ao método polarográfico: 
- menor tempo gasto para cada determinação, cerca de 15 minutos;

- menor quantidade de material biológico, o teste pode ser efetuado com precisāo em quantidades de 1 a $20 \mathrm{mg}$ de vacina $\mathrm{BCG}$ liofilizada;

- sensor que permite leitura direta de variação de temperatura;

- as curvas de consumo de oxigênio são inscritas diretamente no papel de registro;

- facilidade de construção e manejo;

- baixo custo.

A única desvantagem é que, para facilitar a construção, a câmara de reação foi feita em acrílico, material este que mesmo após polimento pode deixar minúsculas ranhuras que facilitam o depósito de partículas contaminantes, exigindo assim maiores cuidados na limpeza da mesma.

Pelo que foi exposto, sugere-se que o método polarográfico poderá ser utilizado como um método de escolha na determinação da viabilidade da vacina $\mathrm{BCG}$ liofilizada. 


\section{6 - CONCLUSŌES}

6.1 - O consumo de oxigênio medido pelo método polarográfico indicou existência de. linearidade desde $1 \mathrm{mg}$ até $20 \mathrm{mg}$ de vacina $\mathrm{BCG}$ liofilizada.

6.2 - O consumo de oxigênio decresceu à medida em que a vacina BCG liofilizada foi exposta a temperaturas crescentes, não apresentando consumo de oxigênio quando exposta durante 15 minutos a partir de $56^{\circ} \mathrm{C}$.

6.3 - Dentre os diluentes utilizados para a reconstituição da vacina BCG liofilizada, 0 que apresentou melhor resultado foi a solução fisiológica tamponada adicionada de $0,3 \%$ de Tween 80 .

6.4 - Os métodos polarográfico, respirométrico de Warburg e contagem de colônias foram comparáveis entre si segundo as análises estatísticas.

6.5 - O método polarográfico apresentou-se reprodutível em diferentes lotes de vacina.

6.6 - O método polarográfico mostrou-se confiável e conveniente para a determinaçāo da viabilidade no controle de qualidade da vacina BCG liofilizada, por proporcionar resultados rápidos, seguros e com consumo mínimo de material biológico. 


\section{7- REFERENCIAS BIBLIOGRÁFICAS}

AMARAL, D. \& BACILA, M. Determinação da galactose oxidase pelo eletródio de. oxigênio. Arq. biol. Tecnol., 12:179-186, 1967.

BACILA, M. O eletródio de oxigênio no estudo do metabolismo de microorganismos. Rev. bras. Microb., 1(2): 117, 1959.

BACILA, M. \& VOSS, D. Subcellular components of rat cerebrum. An. Acad. bras. Cienc., 39 (1):169-173, 1967.

BACILA, M.; ROSA, R.; RODRIGUES, E.; LUCCHIARI, P.H.; ROSA, C.D. Tissue metabolism of the ice-fish Chaenocephalus Aceratus Loenberg. Comp. Biochem. Physiol., 92 B (2): 313-318, 1989.

BAUMBERGER, J.P. The relation between the "oxidation - reduction potential" and the oxygen consumption rate of yeast cell suspensions. Cold Spr. Harb. Symp. quant. Biol., 7: 195-215, 1939.

BERQUO, E.S.; PACHECO de SOUZA, J.M.; GOTLIEB, S.L.D. Bioestatistica. 1.ed.rev. São Paulo, Editora Pedagógica e Universitária Ltda, 1981. 350 p.

BIER, O. Vacinação contra a tuberculose. In: Microbiologia e Imunologia. 24. ed São Paulo, Melhoramentos, 1985. p. 721-722.

BONICKS, R.; JUHASZ, S. E.; DIEMER, U. Studies on the nitrate reductase activity of mycobacteria in the presence of fatty acids and related compounds. Am. Rev. Compounds. Dis, 102 : 507-515, 1970.

BORREMANS, M.; WECKX, M.; VERHOFSTADT, R. A comparison of the rate of oxygen uptake and the adenosine triphosphate content of routine and experimental BCG preparations.J. Biol. Stand., 11: 205-212, 1983.

BRASIL. MINISTÉRIO DA SAÚDE. O refrigerador na conservaçāo de vacinas. Programa Nacional de Imunizações - PNI - Brasil. Rio de Janeiro, Artes Gráficas da FSESP, 1979.

BRETEY, J. Historique de la decouverte du BCG. In: HENNESSEM, W.ed. International Symposiumon BCG Vaccine. Basel, S. Karger AG, 1971. p. 103-108 (Symp. Ser. Immunobiol. Stand, v.17). 
BUNCH-CHRISTENSEN, K. Control methods on vaccine lots with reference to the meaning of different viability tests In: HENNESSEM, W.ed. International Symposium on BCG Vaccine. Basel, S. Karger AG, 1971. p. 199-204 (Symp. Ser. Immunobiol. Stand, v.17).

CALMETTE, A.; BOQUET, A.; NEGRE, L. Contribution à l'étude du bacille tuberculeux bilie. Ann. Inst. Pasteur, 35: 561-570, 1921.

CHANCE, B. \& WLLIAMS, G.R. A simple and rapid assay of oxidative phosphorylation. Nature, 175: 1120-1121, 1955.

CICOGNNA, A.C.; SPADARO, J.; TUCCI, P.J.F.; BREGAGNOLLO, E.A.; RODRIGUES, M.A.M.; CURI, P.R.; LUCCHIARI, P.H. Changes in myocardial and coronary sinus blood oxygen tension induced by asphyxia and reoxygenation. Braz. J. Med. Biol. Res., 21: 585-590, 1988.

COBBOLD, R.S.C. The oxygen electrode. In: Transducers for biomedical measurements: principles and applications. Toronto, John Wiley \& Sons, Inc., 1974. p. 380.

DAVIES, P.W.\& BRINK, F. Direct measurement of brain oxygen concentrations with a platinum electrode. Fed. Proc., 1 (1): 19, 1942.

DAVIES, P.W. The oxygenation cathode. In: NASTUCH, W. ed. Physical technique in biological research. New York/ London Academic Press, 1962. p. 137-179.

DEWHURST, D.J. An introduction to medical instrumentation. 2.ed. Sydney, Pergamon Press, 1976.

ENGBAEK, H.C. \& ORSKOV, J. Germination and growth of BCG vaccine followed by the direct agar microscopy on Dubos' Media. II. Acta Path. microbiol. scand, 31: 360-376, 1952.

ENGIBAROV, A; CHOUCHKOVA, M.; KOYCHEV, C. Studies on the quality control of BCG vaccine; laboratory examinations and postvaccination control in the field. Develop. biol. Standard., 58: 163-171, 1986.

FATT, I. Measurement of oxygen tension in tissue and microbiological suspensions. In: Polarographic oxygen sensor. Its theory of operations and its application in biology, medicine and technology. Cleveland, C.R.S. Press, Inc., 1976. p.63. 
GHEORGHIU, M; AUGIER, J; LAGRANGE, P.H. Maintenance and control of the french BCG strain 1173 - P2 (Primary and Secondary seed - lots) Bull. Inst. Pasteur, 81: 281-288, 1983.

GHEORGHIU, M \& LAGRANDERIE, M. Mesure rapide de la viabilité du BCG par dosage de l'ATP. Ann. Microbiol., 130(2): 147-156, 1979

GHEORGHIU, M; LAGRANDERIE, M; BALAZUC, A.M. Methode rapide de controle sur le terrain de la viabilite du vaccin BCG par dosage de l'ATP.J. Biol. Standard. 12: 257-264,1984.

HAHN, C.E.W.; DAVIES, A.H.; ALBERY, W.J. Eletrochemical improviment of the performance of $\mathrm{PO}_{2}$ electrodes. Respir. Physiol, 25: 109-135, 1975.

KANTOR, I; CETRANGOLO, R.; MANSILLA, C.A. Vacuna BCG liofilizada; normas para efectuar los controles de calidad de la vacuna. Rev. argent. Tuberc., 44(4): 87-94, 1983.

LOWRY, O.H.; ROSEBROUGH, A.J.; FARR, L.; RANDALL, R. Protein measurement with the folin phenol reagent.J.Biol. Chem., 193: 265-275, 1951.

LUCCHIARI, P.H. Circuito polarográfico optimizado para determinaçāo de níveis de oxigênio intracerebral de rato. Botucatu, 1978. (Tese de Livre Docência. Instituto Básico de Biologia Médica e Agrícola).

LUCCHIARI, P.H. \& HOSHINO, K. Inovação de circuito polarográfico para a determinaçāo de variações dos níveis de oxigênio em meios biológicos. Rev. Cienc. bioméd., Sāo Paulo, 1: 51-62, 1980.

LUCHIARI, P.H.; FEOFILOFF, E.F.; BOSCARDIM, A.T.; BACILA, M. A technique for the determination of the avaliable oxygen in living carp (Cyprinus carpio) muscle. Com. Biochem. physiol, 78A: 675-679, 1984.

LUCCHIARI, P.H.; FANTA, E; BACILA, M. The effect of temperature on the muscle oxygen levels in Antarctic Fish. Proc NIPR Symp. Polar Biol, 2: 117-122, 1989. 
MALUCELLI, M.I.C.; NIERO, R.; LUCCHIARI, P.H.; BACILA, M. Posible utilización del método polarográfico, en la determinación de la viabilidad de la vacuna BCG liofilizada. In: CONGRESO PANAMERICANO DE LA UNION LATINOAMERICANA DE SOCIEDADES DE TISIOLOGIA(ULAST), 24.Anales. Buenos Aires, 1990a. p. 20.

MALUCELLI, M. I. C.; NIERO, R; LUCCHIARI, P. H.; BACILA, M. Otimização na determinação do consumo de oxigênio da vacina BCG liofilizada - Método Polarografico. In: SIMPOSIO SOBRE CIENCIAS MÉdICAS E BIOLOGICAS, 1. Anais Curitiba, Universidade Federal do Paraná, 1990b. p.19.

MEDINA, H; VOSS, D.O.; BACILA, M. The determination of oxygen uptake from perfusion liquids by isolated whole heart. An. Acad. bras. Cienc., 39(1): 175-177, 1967.

MICKEL, T.J.; QUETIN, L.B.; CHILDRESS, J.J. Construction of a polarographic oxygen sensor in the laboratory. In: GNAIGER, E \& FORSTNER, H., ed. Polarographic oxygen sensors. Aquatic and physiological applications. Berlim, Springer - Verlag, 1983. p. 81.

MILSTIEN, J.B. \& GIBSON, J.J. Quality control of BCG vaccine by the World Health Organization; a review of factors that may influence vaccine effectiveness and safety. Bull. Org. Mond. Sante, 68(1): 93-108, 1990.

MURRAY, C.J.L.; STYBLO, K; ROUILLON A. Tuberculosis en los países en desarrollo; magnitud, intervenciones y costos. Bol. Unión Internac. Tubercul. Enf. Resp., 65(1):6-26, 1990.

ORGANIZACION PANAMERICANA DE LA SALUD. Control de tuberculosis en America Latina; manual de normas y procedimientos para programas integrados. OMS Publicación Cientifica, (376): 5-15, 1979.

ORGANIZACION PANAMERICANA DE LA SALUD. Control de la tuberculosis; manual sobre metodos y procedimentos para los programas integrados. OMS Publicación Científica (498): 10-20, 1987.

ORGANISATION MONDIALE DE LA SANTE. Comité OMS d'experts de la standardisation biologique. Suisse, 1987. p.64 (Serie de Rapports techniques, 745). 
ORSKOV, J. \& ENGBAEK, H.C. Germination and growth of BCG vaccine followed by the direct agarmicroscopy on Dubos' Media. I. Acta pathol. microbiol. scand, 30: 395- 398, 1952.

PACHECO C.R. \& MAGAÑA, F. A cien años del descubrimiento del bacilo de la tuberculosis. Foletto conmemorativo de la Direción General de Control de la Tuberculosis y de las enfermedades del Aparato Respiratório. México, Secretaria deSalud, 1982. p. 17-28.

PETERING, H.G. \& DANIELS, F. The determination of dissolved oxygen by means of the dropping mercury electrode, with applications in biology. J. Amer. Chem. Soc., 60: 2796-2802, 1938.

PUGA, A.H. Evaluacion de una preparacion interna de referencia para la cuenta viable de la vacuna BCG. México, 1986, p.79 ( Teses Químico Bacteriologo Parasitologo. Instituto Politécnico Nacional. Escuela Nacional de Ciências Biológicas).

SAKATE, M; VERCESI, L; HENRY, M.A.C.A.; LUCCHIARI, P.H., Polarography of walker tumor submitted to radio therapy. Tumori, 73: 555-558, 1987.

SĀO PAULLO. SECRETARIA DE ESTADO DA SAÚDE. Norma do Programa de Imunização - Sistema Unificado e Descentralizado de Saúde (SUDS) do Estado de São Paulo - Comissão Permanente de Assessoramento em Imunizaçōes, São Paulo, 1988.

SKERMAN, B.D. \& MILLIS, N. The application of the polarograph to the determination of oxygen concentration and oxygen consumption rates in bacterial culture media. Aust. J. exper. Biol. med. Sci., 27: 183-195, 1949.

SLATER, E.C. Manometric methods and phosphate determination. In: ESTABROOK, R.W. \& PULLMAN, D.E. ed. Oxidation and phosphorilation. New York, Academic Press, 1967. p. 19-29. (Methods in Enzimology, v.10).

SMITH, F.G.W. ed. Handbook of marine science. Miami, CRC Press, 1974. v 1. p.38. ten DAM, H.G. Research on BCG vaccination. Advanc. Tuberc. Res., 21: 79-106, 1984. 
UNGAR, J.; MUGGLETON, P.W.; DUDLEY, J.A.R.; GRIFFITHS, A. Preparation and properties of a freeze - dried BCG vaccine of increased stability. Brit. Med. J., 2: 1086-1089, 1962.

Van HEMERT, P.A. \& TIESJEMA, R.H. Possible use of the oxygen uptake rate in the evaluation of BCG vaccines.J. Biol. Standard., 5: 121-129, 1977.

Van Den HEUVEL, N.; TIESJEMA, R. H.; Van HEMERT, P. A., Optimization measurement of oxygen uptake rate of BCG with the Gilson oxygraph. Antonie Van Leeuwenhoek, J. Microbiol Serol, 47: 185-186, 1981.

VILELLA, G.G.; BACILA, M.; TASTALDI, H. Técnicas manométricas. In: Técnicas e experimentos em Bioquimica. Rio de Janeiro, Guanabara - Koogan, 1973. p. 367.

VOSS, D.O.; COWLES, J.C.; BACILA, M. A new oxygen electrode model for the polarographic assay of cellular and mitochondrial respiration. Analyt. Biochem., 6: 211-222, 1963.

WORLD HEALTH ORGANIZATION. Guidelines for the use of BCG vaccine in country programes. WHO/ TB/75.101.

WORLD HEALTH ORGANIZATION. Sponsored international quality control of BCG vaccine. WHO/TB Technical Guide/ 77.8 Unpublished working document.

WORLD HEALTH ORGANIZATION. In vitro assays of BCG products. WHO/ TB Technical Guide/77.9 Unpublished working document.

WORLD HEALTH ORGANIZATION . Comité OMS d'experts de la standardisation biologique. Revised requirements for dried BCG vaccine. Suisse, 1979. p. 116-147 (WHO Technical Report Series, 638).

WORLD HEALTH ORGANIZATION. Manual of tests on vaccines in the expanded programme on immunization. BLG/ UNDP/ 82.1 Rev.1, p. 31-52. Unpublished working document. 